\title{
White Selves: Conceptualizing and Measuring a Dominant-Group Identity
}

\author{
Eric D. Knowles \\ Stanford University
}

\author{
Kaiping Peng \\ University of California, Berkeley
}

\begin{abstract}
This article addresses the nature and measurement of White racial identity. White identification is conceptualized as an automatic association between the self and the White ingroup; this association is fostered through social exposure to non-Whites and serves to link self- and ingroup evaluations. Four studies validated a measure of White identification against criteria derived from this model. In Study 1, the White Identity Centrality Implicit Association Test (WICIAT) predicted response latencies in a task gauging self-ingroup merging. In Study 2, the WICIAT correlated with census data tapping exposure to non-Whites. In Studies 3 and 4, the WICIAT predicted phenomena associated with the linking of selfand ingroup evaluations: identity-related biases in intergroup categorization (Study 3) and self-evaluative emotional reactions to ingroup transgressions (Study 4). Together, the findings shed light on the antecedents and consequences of White identity, an often-neglected individual difference construct.
\end{abstract}

Scholars from across the social sciences have come to recognize that racial identification - one's sense of belonging to a racial or ethnic group — shapes personal beliefs, intergroup behavior, and other important outcomes (Cross, 1991; Helms, 1994; Perry, 2002; Phinney, 1996; Rowley, Sellers, Chavous, \& Smith, 1998). The great majority of this research has focused on identification among members of racial minorities (Phinney, 1996). Increasingly, however, social scientists seeking a fuller understanding of pressing social problems, such as racial inequality and discrimination, have turned their attention to the ways in which members of the traditionally dominant group in Western society-Whites-think and feel about their race (Delgado \& Stefancic, 1997). ${ }^{1}$ For example, sociologists have begun to chart the ways in which different forms of White identity impact Whites' cognizance of race privilege, acknowledgment of the role of White racism in creating inequality, and ability to grasp the structural (as opposed to attitudinal) dimensions of racism (Frankenberg, 1993; McIntyre, 1997; Perry, 2002).

In contrast to other social scientists' keen interest in Whites' experience of racial identity, personality and social psychologists have been slow to bring their unique methods and perspectives to bear on White identification. Indeed, as Phinney (1990) noted, "identity among members of a dominant group in society, although it can be conceptualized, has apparently not been studied empirically" (p. 500). This assertion, though more than a decade old,

Eric D. Knowles, Graduate School of Business, Stanford University; Kaiping Peng, Department of Psychology, University of California, Berkeley.

We thank Jack Glaser, Serena Chen, David Sherman, Samuel Gosling, Phillip Atiba Goff, Brian Lowery, Lauren Wichterman, Daniel Ames, Melissa Williams, and Sanjay Srivastava for helpful comments on previous versions of this article. We also thank Linda Tropp for help in setting up the trait self-descriptiveness task; Lorraine Martinez for advice regarding the design of Study 4; and Tamsin Levy, Melody Chao, Audrey Wong, and Paul Piff for help with data collection.

Correspondence concerning this article should be addressed to Eric D. Knowles, Graduate School of Business, Stanford University, 518 Memorial Way, Stanford, CA 94305-4910. E-mail: knowles_eric@gsb.stanford.edu rings true today. A PsycINFO search for any relevant combinations of the terms White/Caucasian/dominant/dominant group, racial/ethnic/social, and identity/identification yielded only 82 matches, just one of which came from a social or personality psychology journal. Empirical psychology's stance toward White identity appears to echo the now-criticized sociological view of Whiteness as inherently "invisible," "transparent," or "unmarked"-an attribute that, despite its power to shape lives, is seldom noticed by those who possess it (Flagg, 1993; Frankenberg, 2001). If they mention Whiteness at all, social psychologists have often relegated it to the role of cognitive "default"-only deviations from which attract attention and trigger cognitive processing (e.g., Smith \& Zarate, 1992; Zarate \& Smith, 1990). In the broadest sense, then, the present work strives to show that White-far from being inert-is a psychologically salient self-categorization worthy of focused study. More specifically, we provide concrete insights into the antecedents and cognitive-emotional consequences of identification with the White group.

We accomplish these overarching goals in the context of validating a measure of White identification: the White Identity Centrality Implicit Association Test (WICIAT). The WICIAT - an adaptation of Greenwald, McGhee, and Schwartz's (1998) Implicit Association Test (IAT) — conceptualizes White identification as the degree to which an individual has incorporated White ingroup membership into his or her self-concept. In making our case for the validity of the WICIAT, we document relations between the measure and criteria drawn from a theoretical model of the antecedents and consequences of White racial identification (see Figure 1). This model posits that White identification derives (in part) from individuals' social exposure to non-Whites and subsequently shapes individuals' cognitions and emotions by binding evaluations of the self to those of the ingroup (Tajfel, 1978).

\footnotetext{
${ }^{1}$ On our use of the term, a dominant group need not be a numerical majority (although it often will be). Rather, a group is dominant if it possesses a disproportionate share of societal resources, privileges, and power. As will become apparent, it is this power-related dimension of dominance that guided our approach to the measurement of White identity.
} 


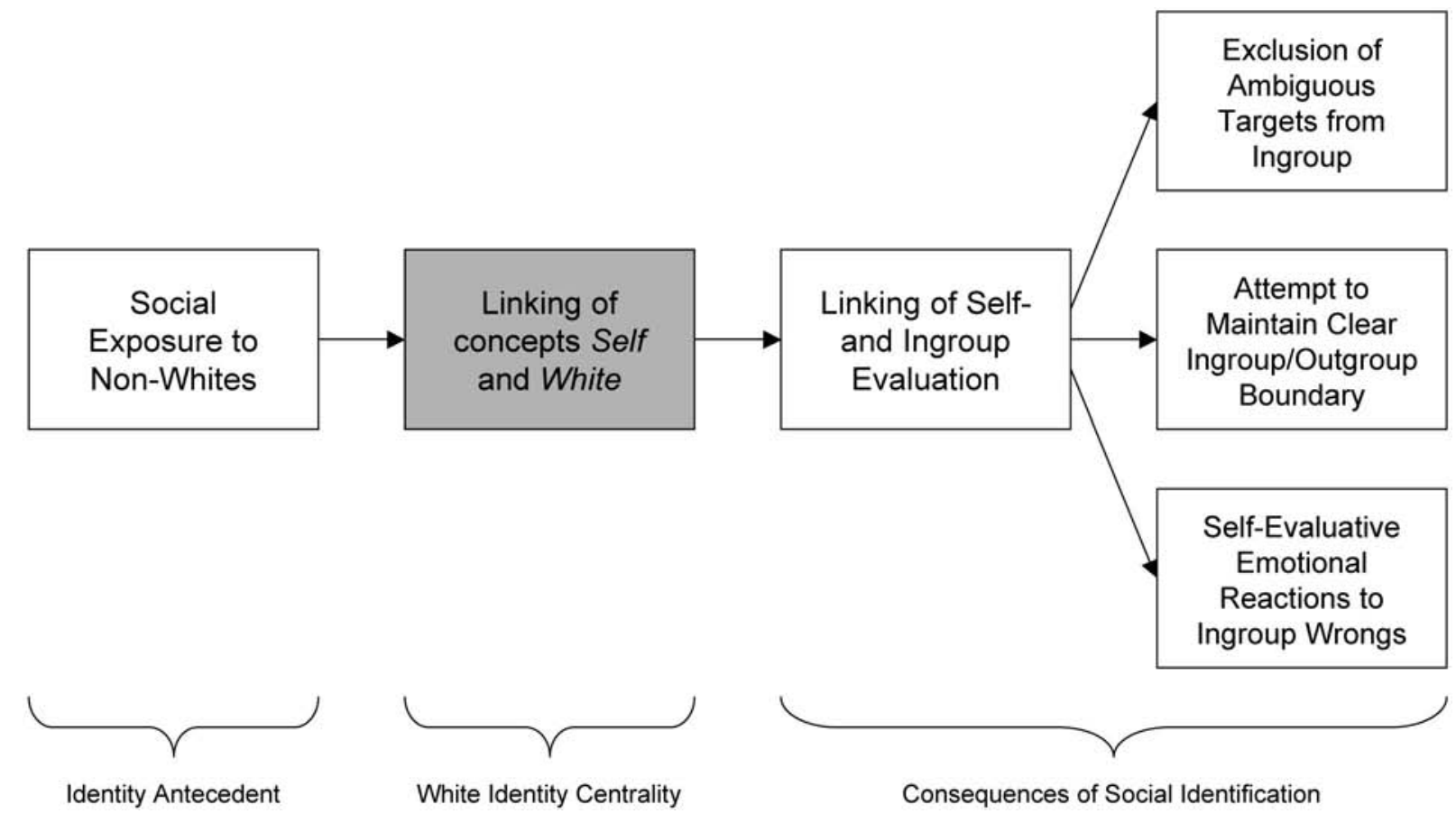

Figure 1. Proposed model of the formation and effects of White ingroup identification.

Why Study White Racial Identification?

Racial inequality and discrimination have long been, and rightly remain, primary explananda of the social sciences. For their part, personality and social psychologists have tended to explain these pressing problems in terms of dominant-group members' negative attitudes toward subordinate groups (Mackie \& Smith, 1998). Although this prejudice-centered approach has yielded a wealth of insights, comparatively little research has focused on Whites' experience of their own racial identity, independent of their views about particular outgroups. Even social identity theory (Tajfel, 1978), which deals centrally with individuals' evaluations of the ingroup, casts outgroup prejudice as the proximal cause of discriminatory behavior (Sidanius, Van Laar, Levin, \& Sinclair, 2004).

Recently, a number of psychologists have begun to address how dominant-group members' feelings about the ingroup per se impact intergroup behavior and policy preferences (Branscombe, 1998; Brewer, 1999; Gaertner et al., 1997; Iyer, Leach, \& Crosby, 2003; Lowery, Unzueta, Knowles, \& Goff, 2004; Sidanius et al., 2004). Such effects arguably presuppose that dominant-group members experience some sense of connection, or identification, with the ingroup category. Thus, researchers interested in the impact of White identification on intergroup behavior may benefit from a conceptual and psychometric analysis of the construct.

\section{Conceptualizing White Racial Identity}

Social and personality psychologists have commonly understood racial identification to be a special case of social identification (Deaux, 1996). As such, racial identification has most often been analyzed from the perspective of social identity theory (Tajfel
\& Turner, 1986) and self-categorization theory (Turner, Hogg, Oakes, Reicher, \& Wetherell, 1987), both of which are predicated on the notion that membership in a group may be incorporated into an individual's self-concept (Smith \& Henry, 1996). Newer alternatives to traditional identity theories, such as Greenwald and colleagues' unified theory of social cognition (Greenwald et al., 2002), echo these theories' basic conceptualization of social identification: that of a linkage between cognitive representations of the self and the ingroup. As Deaux (1996) argued, this process of defining oneself in terms of a group category is a necessary, and perhaps even sufficient, condition for social identification. By extension, the degree of merging between self and group representations-identity centrality - is a fundamental dimension along which individuals differ in social identity (Deaux, 1996; Turner et al., 1987).

Smith and Henry (1996) noted that, despite the importance of the "socially extended self" to social psychological theories of identity, evidence for the merging of the self-concept with group representations has been largely indirect. In order to provide more direct evidence, these researchers adapted a procedure originally developed by Aron, Aron, Tudor, and Nelson (1991) to assess the merging of representations of the self and close others. Smith and Henry (1996) had participants rate themselves and a salient ingroup (e.g., liberal arts majors or engineering majors) on a number of trait dimensions. On the basis of these ratings, traits were then divided into match traits, in terms of which participants saw themselves as similar to the ingroup, and mismatch traits, on which participants saw themselves as unlike the ingroup. In a subsequent computer task, participants took longer to decide whether mismatch traits were self-descriptive than they did match traits. This pattern, in which perceived consistency between self 
and ingroup facilitated self-descriptiveness judgments, suggests a close mental association between the self-concept and the ingroup representation (Smith \& Henry, 1996).

Several self-report scales have been developed to measure individual differences in the merging of self and ingroup representations (i.e., identity centrality). Tropp and Wright's (2001) Inclusion of the Ingroup in the Self Scale (IIS) presents participants with seven pairs of circles increasing in overlap. One circle in each pair represents the ingroup of interest and the other the self; participants are simply asked to choose which pair of circles best represents how they view their relationship to the ingroup. In a compelling demonstration of convergent validity, Tropp and Wright (2001) used the IIS to predict the magnitude of the selfingroup consistency effect in Smith and Henry's (1996) reaction latency task. Other measures of identity centrality rely on a more traditional, verbal format. For instance, Sellers and colleagues' (1997) Multidimensional Inventory of Black Identity (MIBI) includes a Centrality subscale that measures the degree to which a person defines himself or herself in terms of race, and Luhtanen and Crocker's (1992) Collective Self-Esteem Scale (CSE) contains an Identity subscale that measures self-definition in terms of the group.

\section{Measuring White Racial Identity Centrality}

One obvious strategy for assessing White identity centrality is to use existing self-report measures of identity, such as those discussed above, and to alter items where necessary to refer to the White ingroup. However, though such measures have been amply validated in certain contexts (e.g., the MIBI in the context of Black identity), there is good reason to believe that less-reactive implicit measures will prove especially useful in measuring dominantgroup identity.

A large and growing number of American Whites adhere to a philosophy prescribing that racial differences be ignored in favor of pan-human characteristics (Bonilla-Silva, 2003). This "colorblind" ideology appeals to members of the dominant racial group in part because it spares them the discomfort of considering the many unearned advantages conferred by Whiteness (Bonilla-Silva, 2003; Brown et al., 2003; Frankenberg, 1993; Lipsitz, 1998). Colorblind ideology may, in turn, lead its adherents to view any acknowledgment of racial differences as racist-and thus to feel uncomfortable reflecting openly on their experience of racial identity (Frankenberg, 1993; Perry, 2001). This is evident in the words of one White informant who, when asked to recall the first time she noticed that someone was a different color from her, claimed never to have "paid that much attention... I I guess [my father] was prejudiced, but . . I'm still not prejudiced" (Frankenberg, 1993, p. 146). Having equated noticing race with racism, many informants downplayed their cognizance of being White (Frankenberg, 1993).

The social sensitivity of White racial identification suggests against simply modifying questionnaires designed to assess nonWhite racial identity centrality for use with Whites. Although it may be deemed socially appropriate for non-Whites to cite their racial identity as an important aspect of the self, Frankenberg's (1993) work suggests that this may not be generally true for Whites. For many Whites, especially those who strongly embrace colorblindness, demand characteristics will likely weaken the validity of explicit measures of White identity. Specifically, a por- tion of the variance in self-report measures of White identity would likely be attributable to individual differences in selfpresentational concerns. We therefore chose to develop an implicit measure of White identity centrality based on the IAT, which has been shown to be largely immune to demand characteristics (Greenwald et al., 1998).

\section{Using the Implicit Association Test to Measure White Racial Identification}

The IAT, a response latency task administered by computer (Greenwald et al., 2002, 1998), is a general testing framework for assessing the magnitude of cognitive associations between pairs of categories. The IAT has the advantage of measuring automatic associations (Greenwald \& Banaji, 1995) over which individuals have little or no conscious control and is therefore relatively unaffected by individuals' attempts to present themselves in socially desirable ways.

The WICIAT operationalizes White identity centrality as an automatic association between the concepts White and self. Although most Whites can be expected to possess some automatic association between White and self, this association should be particularly strong among Whites for whom membership in the White group is a central component of the self-concept-that is, Whites high in racial identity centrality. Because the IAT has successfully been used to measure social identification in other domains (Greenwald et al., 2002; Greenwald \& Farnham, 2000), we expected it to provide an effective measure of White identity centrality as well. $^{2}$ (The structure of the WICIAT is described in detail in Study 1.)

\section{Validation Criteria}

We chose five convergent criteria against which to evaluate the construct validity of the WICIAT (see Table 1). The first criterion gauges White identity centrality per se (i.e., merging between individuals' representations of the self and White ingroup). The remaining four criteria were derived from a proposed model of the formation and effects and White racial identification (see Figure 1). In this model, social exposure to non-Whites increases White identity (McGuire, McGuire, Child, \& Fujioka, 1978; Perry, 2002), identification forges a link between evaluations of the self and the White ingroup (Tajfel, 1978), and this link, in turn, produces several well-documented social identity effects, described below.

\section{Trait Self-Descriptiveness Task (Study 1)}

As discussed previously, Smith and Henry's (1996) trait selfdescriptiveness task gauges individuals' incorporation of ingroup representations into the self-concept. Given its status as a relatively direct measure of ingroup identification, and its use in validating another measure of identity centrality (Tropp \& Wright, 2001), we

\footnotetext{
${ }^{2}$ In naming the WICIAT, we chose the term identity centrality in order to underscore continuities between our work and that of other research on individual differences in racial identification (e.g., Sellers et al., 1997) However, it would have been equally appropriate to use the term implicit race identity (Greenwald et al., 1998), highlighting our debt to recent work on implicit social cognition.
} 
Table 1

Overview of Validation Strategy for the WICIAT

\begin{tabular}{|c|c|c|}
\hline Criterion type & Validation construct & Validation measure \\
\hline \multicolumn{3}{|l|}{ Convergent } \\
\hline $\begin{array}{l}\text { Alternative test of identity } \\
\text { centrality }\end{array}$ & $\begin{array}{l}\text { Mental association between self-concept } \\
\text { and White ingroup }\end{array}$ & $\begin{array}{l}\text { Trait self-descriptiveness task } \\
\quad \text { (Study 1) }\end{array}$ \\
\hline Identity antecedent & Interracial association & $\begin{array}{l}\text { Census-derived measure of } \\
\text { home county diversity } \\
\text { (Study 2) }\end{array}$ \\
\hline \multirow[t]{3}{*}{ Identity consequence } & Ingroup overexclusion effect & $\begin{array}{l}\text { Threshold for identifying } \\
\text { race-ambiguous faces as } \\
\text { White (Study 3) }\end{array}$ \\
\hline & Categorization latency effect & $\begin{array}{l}\text { Reaction latencies when } \\
\text { categorizing race- } \\
\text { ambiguous faces (Study 3) }\end{array}$ \\
\hline & $\begin{array}{l}\text { Self-evaluative emotional reactions to } \\
\text { ingroup trangressions }\end{array}$ & $\begin{array}{l}\text { Increased guilt, shame, and } \\
\text { embarrassment after } \\
\text { reading about Whites' } \\
\text { lynchings of Blacks (Study } \\
\text { 4) }\end{array}$ \\
\hline \multirow[t]{5}{*}{ Discriminant } & Self-reported identification & $\begin{array}{l}\text { Inclusion of the Ingroup in } \\
\text { the Self Scale (Tropp \& } \\
\text { Wright, 2001; Study 1) }\end{array}$ \\
\hline & & $\begin{array}{l}\text { Multidimensional Inventory } \\
\text { of Black } \\
\text { Identity-Centrality } \\
\text { subscale (Sellers et al., } \\
\text { 1997; Study 1) }\end{array}$ \\
\hline & & $\begin{array}{l}\text { Collective Self-Esteem } \\
\text { Scale-Identity subscale } \\
\text { (Luhtanen \& Crocker, } \\
\text { 1992; Study 1) }\end{array}$ \\
\hline & Implicit ingroup preference & $\begin{array}{l}\text { White ingroup preference } \\
\text { IAT (Greenwald et al., } \\
\text { 1998; Study 1) }\end{array}$ \\
\hline & Self-reported ingroup preference & $\begin{array}{l}\text { Modern Racism Scale } \\
\text { (McConahay et al., 1991; } \\
\text { Study 1) }\end{array}$ \\
\hline
\end{tabular}

Note. Self-report measures of identification were modified to refer to participants' White ingroup. WICIAT $=$ White Identity Centrality Implicit Association Test; IAT = Implicit Association Test.

chose the trait self-descriptiveness task as a validation criterion for the WICIAT. Specifically, we predicted that only White participants with high WICIAT scores would exhibit the self-ingroup match effect indicative of merged representations of self and ingroup.

\section{Individuals' Social Exposure to Non-Whites (Study 2)}

White identity differs from other racial identities in that it is often experienced as the norm (Frankenberg, 1993; McIntyre, 1997; Perry, 2002). As Perry (2002) noted, “. . . [W] [Wite people, by virtue of being members of the dominant group, construct identities defined as 'normal.' ... To be defined as 'normal' means to not be defined at all, to just 'be'” (p. 6). However, though Whites in general may tend not to define themselves in terms of race, cognizance of Whiteness increases with one's exposure to nonWhites (i.e., experience interacting with people of color; Perry, 2002). Support for this claim comes from Perry's (2002) ethnography of White students in two high schools-one in which they were the majority, the other in which they were the minority. Whereas Whites in the majority-White high school often had difficulty even introspecting about their race, students in the
minority-White school exhibited an acute awareness of being White-often expressing elaborate sociopolitical views about their race. This process is consistent with social psychological work suggesting that one's racial or ethnic identity becomes central to the self to the degree that it is perceptually distinctive in one's environment (McGuire et al., 1978; Turner et al., 1987).

In light of evidence that White identity centrality is positively related to Whites' social exposure to non-Whites, we used this factor as a criterion against which to validate the WICIAT. We hypothesized that participants who were raised in geographical areas offering frequent opportunities for interracial associationspecifically, areas where a relatively large percentage of the population is non-White-would score high on the WICIAT. In addition to supporting WICIAT's validity, such a finding would illuminate an important source of individual differences in White racial identification and place limits on the notion that Whiteness is an "unmarked" and invisible identity (see Figure 1).

\section{Racial Categorization Phenomena (Study 3)}

By linking evaluations of the self and ingroup (Tajfel, 1978), social identification is known to affect the processes through 
which perceivers judge targets' ingroup or outgroup membership. We thus chose two identity-related ingroup-outgroup categorization phenomena as validation criteria for the WICIAT. These phenomena result when highly ingroup-identified individuals strive to avoid errors in intergroup categorization.

\section{The Ingroup Overexclusion Effect}

When engaging in ingroup-outgroup categorization, members of a group may seek to avoid "false inclusions" into the ingroupthat is, the mistaken categorization of outgroup members as ingroup members (Castano, Yzerbyt, Bourguignon, \& Seron, 2002; Leyens \& Yzerbyt, 1992; Yzerbyt, Leyens, \& Bellour, 1995). In order to minimize such errors, individuals set a high threshold for categorization in the ingroup, thus tending to relegate groupambiguous targets to the outgroup. According to social identity theory, ingroup overexclusion occurs because the accidental inclusion of outgroup members in the ingroup threatens to undermine individuals' positive evaluation of the ingroup - and, by extension, of the self. This account implies, and recent empirical work suggests (Castano et al., 2002), that ingroup identification is a key factor in determining individuals' tendency to overexclude. Thus, we expected the WICIAT to predict Whites' tendency to categorize White-Black ambiguous targets as outgroup members.

\section{The Categorization Latency Effect}

Members of a group may often strive to be generally accurate when making ingroup-outgroup categorizations (Blascovich, Wyer, Swart, \& Kibler, 1997). As a result, perceivers may scrutinize group-ambiguous targets for a relatively long time before reaching judgments as to their category membership. On the basis of social identity theory, Blascovich and colleagues (1997) reasoned that accuracy motivation in intergroup categorization stems from individuals' desire to maximize the positive evaluation of the ingroup relative to the outgroup; this motivation, in turn, should vary as a function of ingroup identification. We therefore predicted that the WICIAT would be positively associated with long latencies to categorize Black-White ambiguous faces.

\section{Emotional Reactions to Ingroup Transgressions (Study 4)}

The WICIAT relies on a cognitive conception of racial identification (i.e., that of merging between the concepts of self and ingroup). Nonetheless, cognitive identification-by linking evaluations of the self and the White group — should have important affective implications. For instance, to the extent that individuals define themselves in terms of an ingroup, they are likely to feel indirectly responsible for the transgressions of the group (Iyer et al., 2003). This sense of group-based responsibility may, in turn, engender negative self-evaluative emotions, including guilt, shame, and embarrassment (Eisenberg, 2000) on behalf of the ingroup.

Recent research has examined Whites' emotional reactions to moral violations of the White ingroup. Swim and Miller (1999) show that awareness of racism and unearned privilege can lead Whites to experience group-based guilt. Consistent with guilt being a self-evaluative emotion, Iyer and colleagues (2003) show that White guilt is, in part, a function of self-focus: When Whites were encouraged to think of discrimination in terms of Whites' misdeeds, as opposed to Blacks' suffering, they felt more guilt.

The WICIAT can be thought of as a measure of individuals' chronic self-focus as Whites: The higher an individual's level of White identity centrality, the more likely he or she is to shift attention to the self when considering the actions of the ingroup. We thus expected Whites scoring high on the WICIAT to experience more negative self-evaluative emotions (i.e., guilt, shame, and embarrassment) when made aware of the ingroup's historical transgressions than would low-WICIAT individuals. However, consistent with Iyer et al.'s (2003) reasoning, we did not expect WICIAT scores to predict levels of negative other-directed emotions - such as sadness and anger-because these emotions do not imply self-evaluation (Eisenberg, 2000). Because group-based guilt has been shown to predict support for redistributive social policies (Iyer et al., 2003; Swim \& Miller, 1999), including affirmative action, any link between WICIAT scores and selfevaluative emotions would-in addition to attesting to the validity of the instrument-hint at links between White ingroup identification and consequential policy attitudes.

\section{Study 1}

\section{Method}

\section{Participants}

Forty students (25 women, 15 men) at the University of California, Berkeley, and 75 students (53 women, 22 men) at Stanford University took part in the current study. Berkeley participants did so to satisfy psychology course requirements; Stanford participants were each paid \$10. At both universities, participants who had identified their only race or ethnicity to be White during a mass data collection at the beginning of the term were selected (Hispanic Whites were thus not included as participants).

\section{The WICIAT}

A version of the IAT (Greenwald et al., 1998) was used to measure participants' levels of White identity centrality. The WICIAT consisted of 140 trials divided into five blocks. Before beginning the test, participants were instructed to respond as quickly and with as few errors as possible. During the test, stimuli to be categorized were presented in the center of the computer screen. Category labels assigned to the left hand and right hand appeared, respectively, in the upper-left and upper-right corners of the screen. On all trials, participants were required to make the correct response before proceeding to the next trial. Response latencies were recorded for all trials. Blocks were presented in the following fixed order:

White/non-White distinction learning block (20 trials). The first block of trials taught participants to link examples of the concepts White and non-White to different key presses. Specifically, participants were presented with names stereotypically associated with White (e.g., Chip) or non-White (e.g., Tyrone) and were instructed to press one key with the left hand to indicate White names and another key with the right hand to indicate non-White names. The names were those used as instances of the categories White and Black in Greenwald et al. (1998).

Self/other distinction learning block (20 trials). The second block of trials taught participants to link the categories self and other to the same pair of keys used to discriminate White and non-White names in the first block. Thus, participants were presented with self-related words (i.e., I, me, mine, my, myself) or other-related words (i.e., they, them, their, other, themselves), and instructed to categorize them as self or other by pressing the left key or right key, respectively. 
Compatible combination test block (40 trials). The third trial block combined the White/non-White and self-other judgments practiced in the previous two blocks, such that the left key represented White or self and the right key represented non-White or other. Participants then categorized instances of the White/non-White and self-other distinctions, which were presented on alternate trials. Participants high in White identity centrality were expected to respond quickly during this block because keys were assigned to category pairs (White or self and non-White or other) that they should find compatible.

Reversed White/non-White distinction learning block (20 trials). In the fourth block of 20 trials, key assignments for the race-related category distinction were reversed, such that the left key now represented non-White and the right key now represented White.

Incompatible combination test block (40 trials). The fifth and final block of trials combined the self-other judgments with the reversed White/ non-White judgments that participants practiced in the previous block, with the left key representing non-White or self and the right key representing White or other. Participants high in White identity centrality were expected to respond slowly during this block because keys were assigned to category pairs (non-White or self and White or other) that they should find incompatible.

\section{Convergent Validation Task}

We validated the WICIAT against Smith and Henry's (1996) trait self-descriptiveness procedure, which assesses the degree of integration between an individual's self-concept and his or her representation of an ingroup. The task, administered with computers, consisted of two phases. In the first phase, participants rated themselves and the White ingroup on 90 trait adjectives on a Likert-type scale ranging from 1 (extremely unlike) to 6 (extremely like). Trait adjectives were the same as those used by Tropp and Wright (2001) and Smith and Henry (1996). In the second phase, participants made forced-choice judgments of the self-descriptiveness of each trait. Participants were shown each trait on the computer screen, pressing one key if the trait described them and another key if the trait did not describe them; reaction latencies were recorded for all traits. Individuals with merged representations of the self and White ingroup were expected to spend longer making self-descriptiveness judgments for selfingroup inconsistent traits (those on which the self and ingroup are perceived as dissimilar) than for self-ingroup consistent traits (those on which the self and ingroup are seen as similar).

\section{Discriminant Validation Measures}

Measures of ingroup preference. In order to evaluate the discriminant validity of the WICIAT, we administered measures of evaluative bias in favor of the White ingroup (i.e., ingroup preference) - a construct conceptually distinct from identity centrality. We administered two measures of White ingroup preference:

Ingroup preference IAT. We measured implicit ingroup preference with a version of the IAT gauging the automatic association between the categories White and good (relative to Black and bad). This IAT was identical to one reported by Greenwald and colleagues (1998).

Questionnaire measure of ingroup preference. To measure explicit ingroup preference, we administered McConahay et al.'s (1981) Modern Racism Scale (MRS). Strictly speaking this is not a measure of ingroup preference; however, the MRS measures a construct-outgroup derogation-likely to be highly positively associated with ingroup preference. The scale exhibited adequate internal reliability among participants at Berkeley $(\alpha=.82)$ and Stanford $(\alpha=.81)$, as well as in the combined sample $(\alpha=.82)$.

Questionnaire measures of White identity centrality. As discussed earlier, we expected explicit measures of White identity centrality to be confounded with individual differences in self-presentational concerns. We thus predicted that scores on the WICIAT would correlate only weakly with explicit measures of the same construct. We adapted several questionnaires shown to be valid in assessing non-White identity centrality for use with our White participants.

The IIS. We adapted Tropp and Wright's (2001) single-item IIS to measure explicit White identity centrality. To do so, we presented participants with the scale's seven pairs of circles, designating one circle in each pair as Self and the other as Whites. Participants were told to choose the pair of circles that "best represents your relationship to your racial-ethnic group."

Centrality subscale of the MIBI. We adapted the Centrality subscale of the MIBI to measure explicit White identity centrality by altering each question to refer to participants' racial-ethnic group. The scale exhibited adequate internal reliability among Berkeley participants $(\alpha=.83)$ and Stanford participants $(\alpha=.82)$, as well as in the combined sample $(\alpha=$ .82).

Identity subscale of the CSE. As with the MIBI Centrality subscale, we modified the Identity subscale of the CSE for use with Whites by altering the items to refer to participants' racial-ethnic group. The scale (administered only to Berkeley participants) showed adequate internal reliability $(\alpha=.85)$

\section{Procedure}

Participants were run in groups of 1 to 4. Upon arrival, each participant was ushered into a private computer booth. Inquisit (Draine, 1998) and DirectRT (Jarvis, 2004a), which are programs for conducting experiments on Windows systems, were used to present experimental tasks. Tasks were presented in a fixed order: (a) WICIAT, (b) White ingroup preference IAT (Greenwald et al., 1998), (c) trait self-descriptiveness task (Berkeley students only), and (d) explicit questionnaires. Participants were then debriefed as to the nature of the study and dismissed.

Stanford participants completed a subset of the tasks performed by Berkeley participants. All participants completed the WICIAT, the ingroup preference IAT, the MRS, and the IIS. In addition to these tasks, Berkeley participants also completed the trait self-descriptiveness task (Smith \& Henry, 1996) and the CSE.

\section{Results}

None of the effects reported below were moderated by participant gender, sample group (Berkeley vs. Stanford), or their interaction. We therefore collapsed across these variables in the analyses that follow. ${ }^{3}$

\section{Computation of WICIAT Scores}

Reaction latency distributions tend to exhibit a positive skew and thus may violate the normality assumptions of most inferential statistics (Ratcliff, 1993). Therefore, we normalized participants' reaction latency data before computing WICIAT scores. First, following Greenwald and colleagues (1998), we eliminated outliers by replacing latencies under $300 \mathrm{~ms}$ (very short) and over 3,000 ms (very long) with $300 \mathrm{~ms}$ and 3,000 ms, respectively. We then performed a reciprocal transformation on the reaction latency data, dividing latencies for every trial into 1,000 (Ratcliff, 1993). In

\footnotetext{
${ }^{3}$ Male and female participants did not differ significantly on any measure administered in Study 1. The sample groups (Berkeley and Stanford) differed on three measures, with Stanford students scoring lower on the IIS, $t(113)=2.00, p<.05$, higher on the MRS, $t(113)=-4.34, p<.01$, and higher on the MIBI Centrality subscale, $t(113)=3.16, p<.01$.
} 
addition to reining in outliers, the reciprocal transformation had the effect of converting participants' reaction latencies into reaction speeds, with higher values indicating faster responses.

Only blocks three and five of the WICIAT - the compatible and incompatible combination test blocks-entered into the calculation of scores. Each participant's score was assessed with the size of the effect of test block (compatible combination vs. incompatible combination) on his or her reaction speeds. The measure of effect size was Cohen's $d$ (J. Cohen, 1977). Thus, we first subtracted each participant's mean reaction speed in the incompatible combination test block (in which the left and right keys were assigned to White or other and non-White or self, respectively) from his or her mean reaction speed in the compatible combination test block (in which the left and right keys were assigned to White or self and non-White or other, respectively). This difference was then divided by the pooled standard deviation of reaction speeds in the compatible and incompatible combination test blocks. Resulting effect sizes reflect the ease with which participants mapped the category pairs White + self and non-White + other onto single responses, as compared with the pairs non-White + self and White + other. This, in turn, reflects a strong automatic association between the White/non-White distinction and the self-other distinction-and hence strong identification with the White ingroup.

As expected, participants tended to respond more quickly on compatible combination trials than on incompatible combination trials, $t(114)=9.23, p<.01$. Participants' average IAT effect as measured with Cohen's $d$ was $0.55(S D=0.65)$, suggesting that, overall, participants were identified with the White ingroup. The WICIAT distribution was characterized by minimal skewness (.19) and minimal kurtosis (.66) and thus approximated the normal distribution. ${ }^{4}$

\section{Convergent Validity of the WICIAT}

A valid measure of White identity centrality should be capable of identifying participants who, in the trait self-descriptiveness task, exhibit merged representations of the self and White ingroup (Smith \& Henry, 1996; Tropp \& Wright, 2001). Self-ingroup merging is assessed by relating participants' response latencies in the forced-choice phase of the procedure to their earlier Likert ratings of traits' self- and ingroup descriptiveness. Specifically, individuals with merged self and ingroup representations should take longer to judge the self-descriptiveness of self-ingroup inconsistent traits (those seen to describe the ingroup but not the self or the self but not the ingroup) than self-ingroup consistent traits (those that both the self and the ingroup are seen to have or to lack). The hallmark of self-ingroup merging is therefore a crossover Self-Descriptiveness $\times$ Ingroup Descriptiveness interaction for reaction times (Smith \& Henry, 1996). Our primary claimthat only high-WICIAT individuals possess merged representations of self and ingroup-implies that only high-WICIAT participants will exhibit this Self-Descriptiveness $\times$ Ingroup Descriptiveness interaction. In other words, WICIAT scores should predict the magnitude of the Self-Descriptiveness $\times$ Ingroup Descriptiveness interaction for reaction latencies (a WICIAT Score $\times$ Self-Descriptiveness $\times$ Ingroup Descriptiveness interaction; cf. Tropp \& Wright, 2001).

To prepare the data for analysis, we first normalized participants' reaction latencies by (a) discarding latencies shorter than
$300 \mathrm{~ms}$ or longer than 5,000 ms (per Smith \& Henry, 1996) and (b) reciprocally transforming latencies by dividing them each into 1,000 (thus converting latencies into reaction speeds). We then centered the self-descriptiveness and ingroup descriptiveness variables around each participant's mean, multiplied these centered variables to create a Self-Descriptiveness $\times$ Ingroup Descriptiveness interaction term, and mean-centered WICIAT score (Bryk \& Raudenbush, 1992).

Because the data were nested, with 90 reaction latency observations per participant, we tested our hypotheses with hierarchical linear modeling in HLM 6 (Raudenbush, Bryk, Cheong, \& Congdon, 2004). A Level-1 (within-subject) equation was constructed in which self-descriptiveness (SD), ingroup descriptiveness (ID), and their interaction predicted reaction speed. Four Level-2 (between-subjects) equations were created, each of which used WICIAT score (WIC) as a predictor of one within-subject effect (including the within-subject intercept). Thus, we tested the following two-level model, in which $t$ denotes a single observation (i.e., computer trial) and $i$ a single participant:

Level 1: $\operatorname{SPEED}_{t i}=\pi_{0 i}+\pi_{1 i}(\mathrm{SD})_{t i}$

$$
\begin{gathered}
\quad+\pi_{2 i}(\mathrm{ID})_{t i}+\pi_{3 i}(\mathrm{SD} \times \mathrm{ID})_{t i}+e_{t i} \\
\text { Level 2: } \pi_{0 i}=\beta_{00}+\beta_{01}(\mathrm{WIC})_{i}+r_{0 i} \\
\pi_{1 i}=\beta_{10}+\beta_{11}(\mathrm{WIC})_{i}+r_{1 i} \\
\pi_{2 i}=\beta_{20}+\beta_{21}(\mathrm{WIC})_{i}+r_{2 i} \\
\pi_{3 i}=\beta_{30}+\beta_{31}(\mathrm{WIC})_{i}+r_{3 i}
\end{gathered}
$$

The fixed effect of self-descriptiveness on reaction speed was significant, $\beta_{10}=0.021, S E \beta_{10}=0.0058, t(38)=3.68, p<.01$, reflecting that participants were faster to judge traits they had previously indicated described them than traits they had indicated did not describe them. Smith and Henry (1996) reported the same result, attributing it to the fact that people tend to respond "yes" faster than they respond "no." We observed no effect of ingroup descriptiveness, $\beta_{20}=0.00036, S E \beta_{20}=0.0082, t(38)=0.44$, $p=.66$. There was, however, a significant Self-Descriptiveness $\times$ Ingroup Descriptiveness interaction, $\beta_{30}=0.020, S E \beta_{30}=$ $0.0054, t(38)=3.71, p<.01$. We probed this interaction by solving the two-level model for different combinations of low and high self- and ingroup descriptiveness (i.e., one standard deviation above and below the means). We found that participants tended to respond more quickly to self-ingroup consistent traits (average predicted latency $=890 \mathrm{~ms}$ ) than to self-ingroup inconsistent traits (average predicted latency $=936 \mathrm{~ms}$ ). Per the logic of the trait self-descriptiveness task, this Self-Descriptiveness $\times$ Ingroup Descriptiveness interaction suggests that participants tended to have merged representations of the self and the White ingroup.

Turning to the cross-level interactions, WICIAT score was not found to qualify the main effects of self-descriptiveness, $\beta_{11}=$

\footnotetext{
${ }^{4}$ In order to assess the test-retest reliability of the WICIAT, we administered the measure to an independent sample $(N=12)$ twice over a 2 -week period. WICIAT scores correlated highly across the two administrations $(r=.82, p<.01)$. Thus, White identity centrality appears to be a very stable individual difference.
} 
$0.0086, S E \beta_{11}=0.013, t(38)=-0.65, p=.52$, or ingroup descriptiveness, $\beta_{21}=0.022, S E \beta_{21}=0.027, t(38)=0.80, p=$ .43. However, and more importantly, WICIAT score predicted the magnitude of the observed Self-Descriptiveness $\times$ Ingroup Descriptiveness interaction, $\beta_{31}=0.029, S E \beta_{31}=0.011, t(38)=$ $2.60, p<.05$.

In order to visualize the observed WICIAT Score $\times$ SelfDescriptiveness $\times$ Ingroup Descriptiveness interaction, we plotted regression predictions for low and high WICIAT scores (Aiken \& West, 1991); these predictions were converted from reaction speeds into latencies and are presented in bar format (despite the fact that all variables are continuous) in order to render the graph easily comparable to those in previous articles that used the trait self-descriptiveness task (Smith \& Henry, 1996; Tropp \& Wright, 2001). As Figure 2 shows, low scorers (one standard deviation below the mean) on the WICIAT showed no evidence of facilitation on traits in which the White ingroup was deemed similar to the self, whereas high scorers (one standard deviation above the mean) on the WICIAT responded more quickly to self-ingroup consistent traits than to self-ingroup inconsistent traits. Confirming this, simple slope analyses (Aiken \& West, 1991) revealed that the Self-Descriptiveness $\times$ Ingroup Descriptiveness interaction-the hallmark of self-ingroup merging (Smith \& Henry, 1996)—was significant for high scorers on the WICIAT, $t(38)=4.26, p<.01$, but not for low-WICIAT participants, $t(38)=0.90, p=.38$. This suggests that, as predicted, the WICIAT can successfully identify participants whose representations of the self and White ingroup are merged.

Additional evidence for the convergent validity of the WICIAT comes from the fact that scores on the test significantly predicted the magnitude of the Self-Descriptiveness $\times$ Ingroup Descriptiveness interaction, even when any other measure (i.e., the White ingroup preference IAT, MRS, IIS, MIBI Centrality subscale, or the CSE Identity subscale), along with its two- and three-way interactions with self-descriptiveness and ingroup descriptiveness,

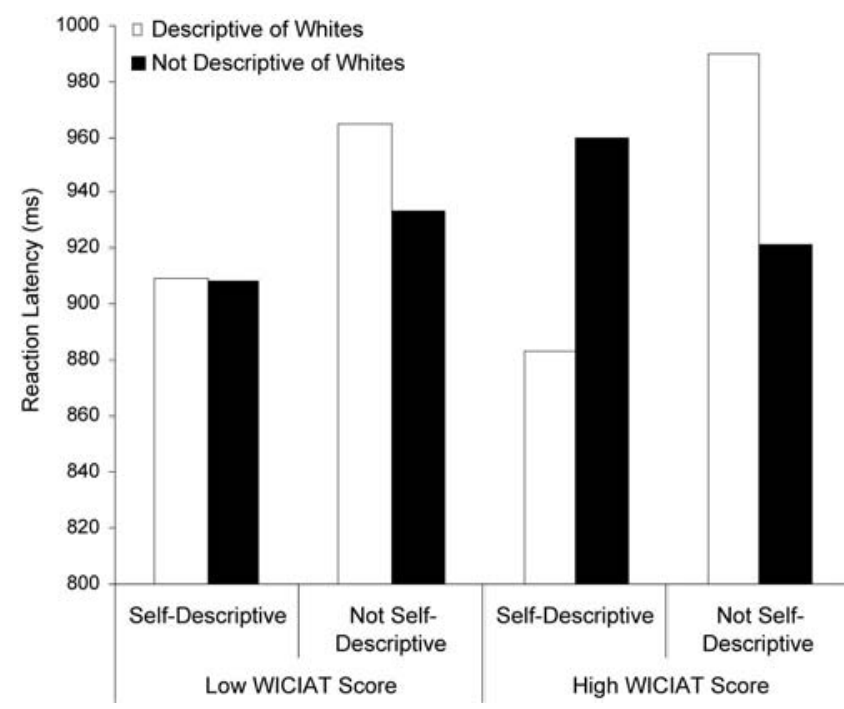

Figure 2. Reaction latencies as a function of trait self-descriptiveness and ingroup descriptiveness for low-WICIAT and high-WICIAT Whites in Study 1 . WICIAT $=$ White Identity Centrality Implicit Association Test. was entered into the two-level model as controls. This held true as well when the two-way interaction between the WICIAT and each other measure was entered into the model in this manner.

\section{Discriminant Validity of the WICIAT}

We next sought to evaluate the discriminant validity of the WICIAT. To do this, we sought to show that little association existed between the WICIAT and two classes of conceptually distinct measures: measures of White ingroup preference and explicit measures of White identity centrality.

Measures of White ingroup preference. We first correlated the WICIAT with the White ingroup preference IAT. The same normalization procedures used for the WICIAT (i.e., outlier screening and reciprocal transformation) were used to normalize ingroup preference IAT data. White ingroup preference IAT scores were then computed with Cohen's $d$ for the effect of test block (incompatible vs. compatible) on reaction speeds. Higher scores reflected the ease with which participants mapped the category pairs White + good and Black + bad onto single responses, as compared with the pairs White + bad and Black + good-and thus preference for the White ingroup. Participants exhibited a marked preference for the White ingroup, responding more quickly on compatible test trials than on incompatible test trials, $t(114)=$ 14.91, $p<.01$. The association between the WICIAT and the White ingroup preference IAT was moderately positive $(r=.35$, $p<.01)$.

We next correlated the WICIAT with the MRS. The correlation was weak yet statistically significant $(r=.21, p<.05)$. Thus, individuals high in implicit White identity centrality exhibited somewhat more explicit racism than did individuals low in White identity centrality.

Explicit measure of White identity centrality. Next, we analyzed the association between the WICIAT and explicit measures of the same construct. The WICIAT failed to correlate significantly with the IIS ( $r=.13, p=.18)$, the MIBI Centrality subscale $(r=.07, p=.47)$, or the CSE Identity subscale $(r=-.002, p=$ .99).

\section{Relative Effectiveness of WICIAT in Predicting the Validation Task}

If the WICIAT is uniquely well-suited to the measurement of White identity centrality, then it should better predict the convergent validation (trait self-descriptiveness) task than do the other measures. In order to assess this, we repeated our analysis of the trait self-descriptiveness task, this time replacing the WICIAT with each discriminant validity measure (i.e., the White ingroup preference IAT, MRS, IIS, MIBI Centrality subscale, and CSE Identity subscale) in the Level-2 equations. Unlike the WICIAT, every other measure failed to significantly predict facilitation on selfingroup consistent traits - that is, to qualify the Self-Descriptiveness $\times$ Ingroup Descriptiveness interaction indicative of selfingroup merging. Moreover, the correlation between the WICIAT and the trait self-descriptiveness task remained significant after partialing out the association between the WICIAT and any other measure. Finally, the relationship between WICIAT score and the trait self-descriptiveness task was significantly stronger than that 
between the trait self-descriptiveness task and any other measure, with the exception of the MRS $(p=.39) .^{5}$

\section{Discussion}

Study 1 provides initial evidence for the convergent and discriminant validity of the WICIAT. As to convergent validity, we showed that the identity centrality IAT predicts a well-accepted measure of the merging of self and group representationsnamely, the trait self-descriptiveness task used by Smith and Henry (1996) and Tropp and Wright (2001). As evidence of discriminant validity, we showed that the WICIAT did not correlate strongly with conceptually distinct measures. Not surprisingly, the test was only moderately or weakly associated with measures of ingroup preference-specifically, the White ingroup preference IAT and the MRS. Although social identity theory (Tajfel, 1978) implies that individuals prefer to identify with ingroups that they view positively and thus that ingroup identification might, under some circumstances, be correlated with ingroup preference, identity centrality and ingroup preference are distinct concepts. Nor was the WICIAT strongly correlated with explicit measures of the same construct. This was expected in light of ethnographic evidence that many Whites are reluctant to admit that Whiteness is central to their self-concept (Frankenberg, 1993; McIntyre, 1997). The fact that the WICIAT failed to correlate strongly with explicit identity measures, coupled with the fact that none of the explicit measures predicted reaction speeds in the trait self-descriptiveness task, suggests that the WICIAT is uniquely well suited to measure the incorporation of White ingroup membership into the self-concept.

In Study 2, we used participants' likely history of social exposure to non-Whites as a criterion against which to further validate the WICIAT. Specifically, we expected the test to vary positively with past interracial contact (McGuire et al., 1978; Perry, 2002). Because questionnaire measures of interracial association are potentially vulnerable to social desirability concerns, we sought a more objective measure of contact. We reasoned that the potential for interracial association in participants' home regions would be proportional to racial diversity within those regions. By using data from the 2000 U.S. Census, we calculated an index of the diversity of participants' home counties-specifically, the percentage of non-Whites in the county population. To the extent that the WICIAT is valid, it should correlate positively with this index.

\section{Study 2}

\section{Method}

\section{Participants}

One hundred students (59 women, $41 \mathrm{men}$ ) at Stanford University participated in the current study in return for $\$ 10$ payments. Participants who had identified their only race or ethnicity to be White during a mass data collection at the beginning of the term were selected (Hispanic Whites were thus not included as participants).

\section{Measures}

Measures of White identity centrality. Participants were administered the WICIAT, as well as two explicit measures of White identity centrality-specifically, modified versions of the IIS and the MIBI Centrality subscale. The MIBI Centrality subscale exhibited adequate internal reliability $(\alpha=.84)$.

Measures of White ingroup preference. We administered implicit and explicit measures of preference for the White ingroup - namely, the White ingroup preference IAT and the MRS. The MRS showed adequate internal consistency $(\alpha=.80)$.

ZIP code form. Participants completed a questionnaire asking them to identity the 5-digit ZIP code in which they "grew up or spent the most time in growing up."

\section{Procedure}

Participants were run in groups of 2 to 6. Upon arrival, participants were seated at testing computers, which were separated by dividers. Experimental materials were presented with MediaLab (Jarvis, 2004a) and DirectRT (Jarvis, 2004b) by Empirisoft Research Software. Explicit measures were presented in random order, followed by implicit measures in random order. Participants were then debriefed as to the nature of the study and dismissed.

\section{Results}

Male and female participants did not differ significantly on any measure administered in the current study, nor did participant gender moderate any of the observed relationships. We therefore collapsed across gender in the analyses below.

We hypothesized that participants' levels of implicit White identity centrality, as measured with the WICIAT, would be positively related to racial diversity in participants' home regions. In order to test this, we first identified participants' counties of origin on the basis of their home ZIP codes. Then, with data from the 2000 U.S. Census, we calculated the proportion of the population represented by non-Whites (including Hispanics of any race) for each of 67 counties where participants were raised. Non-White population proportion varied widely (from $2 \%$ in Union County, PA to $80 \%$ in Honolulu County, HI). WICIAT scores were significantly correlated with White ingroup preference IAT scores $(r=.30, p<.01)$ but not with explicit measures of racial attitudes (i.e., the MRS) or White identity centrality (i.e., the IIS and the MIBI Centrality subscale).

In testing the relationship between home region diversity and the WICIAT, we sought to ensure that any observed effect was not driven by a relationship between diversity and participants' racial attitudes. Thus, through the use of simultaneous multiple regression, we tested the association between home region diversity and the WICIAT, while controlling for participants' explicit and implicit attitudes as measured with the White ingroup preference IAT and the MRS. This analysis revealed a significant positive association between home county diversity and WICIAT scores $(\beta=$ $0.19, p<.05)$. Compared with residents of largely White counties, participants from counties with a substantial non-White population tended to show high levels of implicit White identity centrality as measured with the WICIAT.

We next sought to test whether county demographics were related to either of our explicit measures of White identity cen-

\footnotetext{
5 These comparisons were made by first converting the $t$ statistic for each measure's effect on the Self-Descriptiveness $\times$ Ingroup Descriptiveness interaction into a correlation; we then tested the significance of the differences between these dependent correlations. See Blalock (1972) for relevant formulas.
} 
trality (i.e., the IIS and the MIBI Centrality subscale). In separate, simultaneous multiple regressions, we used counties' proportion of non-Whites to predict each of the explicit identity measures (again controlling for implicit and explicit ingroup preference). However, neither explicit identity measure was significantly related to home region diversity.

\section{Discussion}

Study 2 tested the hypothesis, derived from ethnographic (Perry, 2002) and social psychological (McGuire et al., 1978; Turner et al., 1987) research, that White identity centrality increases with Whites' level of social exposure to non-Whites. We used a demographic variable related to social exposure - the representation of non-Whites in participants' home counties-to predict scores on the WICIAT. As expected, participants from largely non-White regions scored higher in implicit White identity centrality than did participants from predominantly White counties. This suggests that participants' White group membership was made salient-and eventually central to the self-concept-through relatively frequent encounters with non-Whites while growing up. These findings, along with the fact that the WICIAT was the only identity measure significantly associated with diversity, lends credence to our claim that the WICIAT is uniquely well suited to measure White identity centrality.

In Study 3, we sought additional evidence for the construct validity of the WICIAT by determining whether it predicts two intergroup categorization phenomena associated with ingroup identification-namely, the ingroup overexclusion effect (Castano et al., 2002; Leyens \& Yzerbyt, 1992; Yzerbyt et al., 1995) and the categorization latency effect (Blascovich et al., 1997). In this study, White participants categorized photographs of Black and White faces that had been blended together to render them racially ambiguous. Consistent with the Castano et al. (2002) findings, we predicted that individuals high in implicit White identity centrality (as measured with the WICIAT) would be motivated to insulate the White ingroup from outgroup members-and thus would tend to exclude racially ambiguous faces from the White ingroup (the ingroup overexclusion effect). In testing this hypothesis, we operationalized overexclusion as participants' categorization threshold, or the level of blending at which they switch from categorizing faces as Black to categorizing them as White. In light of Blascovich et al.'s (1997) work, we also predicted that high scorers on the WICIAT would spend a relatively long time scrutinizing race- ambiguous faces before reaching category judgments (the categorization latency effect).

Study 3

Method

\section{Participants}

Sixty students (38 women, 22 men) at the University of California, Berkeley, and 58 students ( 40 women, 18 men) at Stanford University took part in the current study. Berkeley participants did so to satisfy psychology course requirements; Stanford participants were each paid \$10. At both universities, participants who had identified their only race or ethnicity to be White during a mass data collection at the beginning of the term were selected (Hispanic Whites were thus not included as participants).

\section{Stimuli}

In order to generate stimuli for use in the current experiment, we began by taking color facial photographs of a Black man and a White man. Adobe Photoshop was used to remove backgrounds and any visible clothing. Pairs of faces were blended using Morph 2.5 (Maxwell, 1994) by Gryphon Software, a morphing program that is run on a Macintosh Power PC. We first specified points of equivalence (i.e., jaw line, nose, pupils) in the pair of original images; the morphing algorithm then interpolated pixels and hues between these equivalent points. To create blends at different proportions, we set the program to interpolate pixels closer in location and hue to one of the original images. Thus, for the 50/50 Black-White image the algorithm interpolated pixels and hues halfway between equivalent points in the original Black and White images, whereas for the 30/70 BlackWhite morph the algorithm interpolated pixels and hues $30 \%$ of the distance from points on the White original image to their equivalent points on the Black original image. This procedure was used to create a BlackWhite race continuum consisting of 11 images ( 2 originals and 9 blends) spaced at $10 \%$ increments (see Figure 3 for sample faces from the continuum).

\section{Procedure}

Participants were brought into a testing room 1 to 3 at a time and seated at computers. Computers were separated from one another by dividers to ensure participants' privacy. Sessions consisted of two randomly ordered task blocks - one in which participants were administered the racial categorization task and the other in which they were administered the WICIAT and the White ingroup preference IAT. At Berkeley, experimental tasks were administered with PsyScope 1.1.2 (J. D. Cohen, MacWhinney, Flatt,

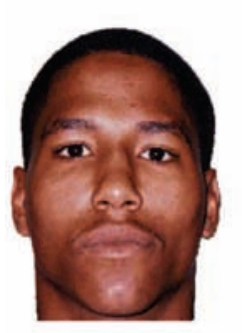

Original Black Face

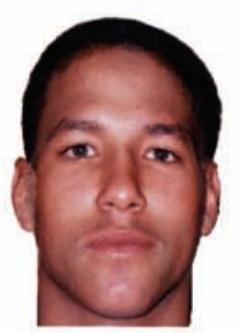

$60 / 40$ Black/White

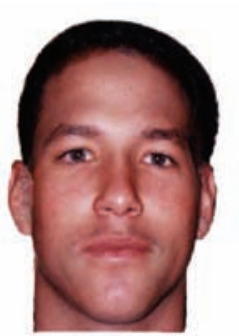

$50 / 50$ Black/White

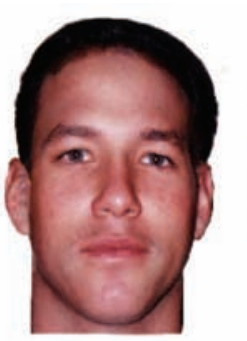

40/60 Black/White

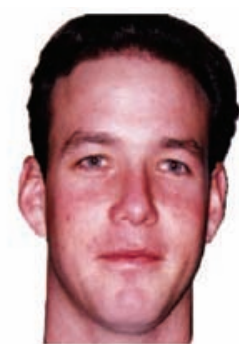

Original White Face

Figure 3. Sample faces from the Black-White continuum used in Study 3. 
\& Provost, 1993) on Macintosh computers; at Stanford, the task was administered on Windows PCs with DirectRT.

Racial categorization task. In the racial categorization task, participants were shown faces from the Black-White continuum in random order until each face had been presented 8 times for a total of 88 trials. Faces were presented against a white background and appeared for $750 \mathrm{~ms}$. To prevent rhythmic responding, the intertrial interval was varied randomly from trial to trial between 500 and 1,250 ms. Participants were required to categorize each stimulus by pressing the $Z$ key for Black and the $M$ key for White. After finishing the experiment, participants were debriefed and dismissed.

IAT task block. In the IAT task block, participants were administered the WICIAT and implicit White ingroup preference IAT (described in Study 1) in random order.

\section{Results}

None of the categorization threshold or reaction latency effects reported below were moderated by participant gender, sample group (Berkeley vs. Stanford), or their interaction. We therefore collapsed across these variables in the analyses that follow. ${ }^{6}$

\section{Calculation of IAT Scores}

We calculated WICIAT and White ingroup preference IAT scores in the manner described in Study 1, such that higher scores reflect greater implicit White identity centrality and implicit preference for the White ingroup.

\section{WICIAT Scores and Categorization Threshold}

Hierarchical nonlinear modeling was used to test the hypothesized relationship between WICIAT scores and the tendency to categorize racially ambiguous faces as Black. In testing this prediction, we sought to ensure that any observed relationship was not driven by an association between WICIAT scores and implicit ingroup preference, as measured with the White ingroup preference IAT. We began the analysis by constructing a within-subject (Level-1) nonlinear equation modeling how each participant's responses in the racial categorization task varied as a function of face stimulus (i.e., morphing ratio), as well as between-subjects (Level-2) linear equations modeling how participants' categorizations differed as a function of WICIAT scores and White ingroup preference IAT scores.

Level-1 equation. In the race-categorization task, participants were shown 11 faces spanning a continuum from Black to White. Each face was presented eight times, making it possible to calculate the probability that a participant categorized a given face as White on a single presentation. Thus, a participant's responses can be visualized by plotting the probability of a "White" response on the $y$-axis against Black-White morphing ratio on the $x$-axis. The tendency to exclude race-ambiguous faces from the White ingroup can then be operationalized in terms of the Black-White categorization threshold, or the point on the $x$-axis at which "White" responses became more likely than "Black" responses. The sigmoid function provided a good fit for participants' responses while allowing the parameterization of categorization threshold:

$$
\text { Level 1: P(WHITE })_{t i}=\frac{1}{1+e^{\pi_{0 i}\left(\pi_{1 i}-\mathrm{MR}_{t i}\right)}}
$$

Here, $\mathrm{MR}_{t i}$ is the morphing ratio from 0 to 1 of a face, $t$, presented to a participant, $i$, such that higher values of $\mathrm{MR}_{t i}$ indicate greater proximity to the White end of the continuum. Variable $\mathrm{P}(\text { WHITE })_{t i}$ refers to the probability from 0 to 1 that the participant categorized a face as "White" on one of its eight presentations. Parameter $\pi_{0 i}$ reflects the maximum slope of the participant's sigmoid curve, and, of greater present interest, $\pi_{1 i}$ reflects the participant's categorization threshold.

Level-2 equations. Having constructed a Level-1 (withinsubject) equation that parameterizes categorization threshold, we next constructed Level-2 (between-subjects) equations to describe the influence of WICIAT score (WIC) and White ingroup preference IAT score (WIP) on maximum slope $\left(\pi_{\mathrm{O} i}\right)$ and categorization threshold $\left(\pi_{1 i}\right)$ :

$$
\begin{gathered}
\text { Level 2: } \pi_{0 i}=\beta_{00}+r_{0 i} \\
\pi_{1 i}=\beta_{10}+\beta_{11}(\mathrm{WIC})_{i}+\beta_{12}(\mathrm{WIP})_{i}+r_{1 i}
\end{gathered}
$$

Here, $\beta_{00}$ and $\beta_{10}$ represent the means around which individuals' response curves vary in terms of maximum slope and categorization threshold, respectively; $r_{0 j}$ and $r_{1 j}$ represent random between-subjects error in maximum slope and threshold. In the second Level-2 equation, $\beta_{11}$ and $\beta_{12}$ represent the effects of participants' WICIAT score and White ingroup preference IAT score, respectively, on categorization threshold $\left(\pi_{1 i}\right)$. In the first Level-2 equation, the maximum slope, $\pi_{\mathrm{O} i}$, of participants' sigmoid curves is allowed to vary randomly between participants but is not treated as a function of IAT scores.

Solution. We used the NLMIXED procedure in SAS (Version 8) to solve the two-level model describing participants' behavior in the categorization task. The intercept for categorization threshold was not significantly different from $0, \beta_{10}=0.05, S E \beta_{10}=0.05$, $t(114)=0.94, p=.35$, indicating that, overall, participants divided the Black-White continuum near the 50/50 point. The effect of White ingroup preference IAT score was not significant, $\beta_{12}=$ $0.10, S E \beta_{12}=-0.05, t(114)=-0.36, p=.72$. However, the effect of WICIAT score was significant, $\beta_{11}=0.37, S E \beta_{11}=$ $0.13, t(114)=2.90, p<.01$, such that individuals with higher WICIAT scores had higher categorization thresholds-and thus excluded more faces from the White ingroup- than did low scorers on the WICIAT.

In order to visualize the effect of participants' WICIAT scores on patterns of racial categorization, we plotted predicted response curves at one standard deviation above and one below the mean on the WICIAT (cf. Aiken \& West, 1991). These curves represent participants' categorizations (i.e., White categorization probability) as a function of morphing ratio at low and high levels of implicit White identity centrality. As can be seen in Figure 4A, WICIAT score predicted participants' categorization profiles such that, compared with low scorers on the WICIAT, high-WICIAT

\footnotetext{
${ }^{6}$ Participants' gender was not significantly related to categorization thresholds or reaction latencies in Study 3. Compared with their Berkeley counterparts, Stanford students exhibited a higher (more restrictive) threshold for inclusion of faces in the White ingroup, $t(114)=2.43, p<.05$. Stanford students also took longer overall to categorize faces, $t(1038)=$ 4.57, $p<.01$.
} 

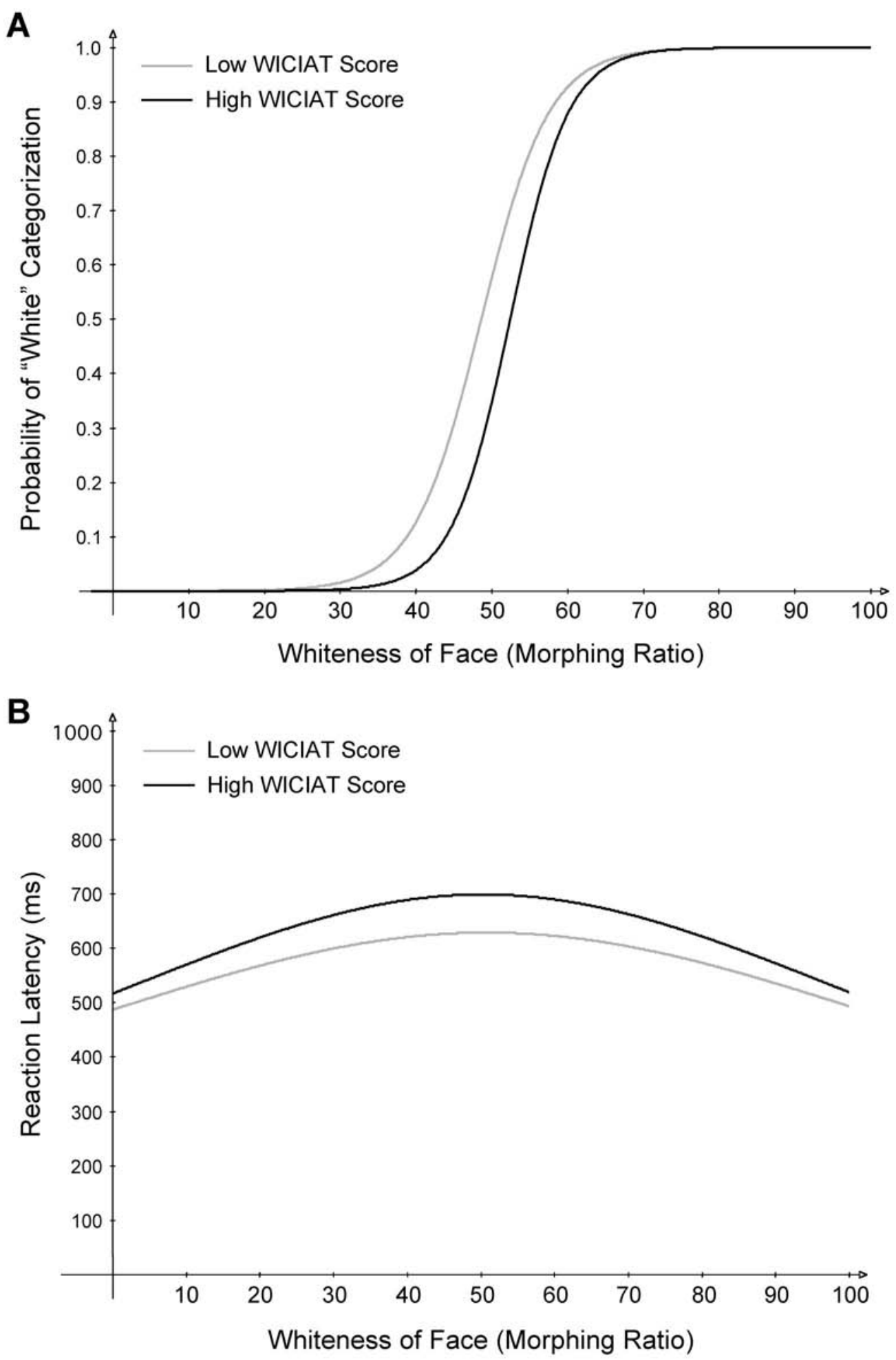

Figure 4. Black-White categorization phenomena as a function of White Identity Centrality Implicit Association Test (WICIAT) scores in Study 3. A: Categorization profiles for high- and low-WICIAT Whites (pattern showing the ingroup overexclusion effect). B: Categorization latencies for high- and low-WICIAT Whites (pattern showing the categorization latency effect). 
participants set a higher threshold for categorization of faces as White. $^{7}$

\section{WICIAT Scores and Categorization Latencies}

The latency effects reported below were not moderated by participant gender, sample group (Berkeley vs. Stanford), or their interaction. Therefore, we collapsed across these variables in the following analyses.

In order to normalize the reaction time distribution, we subjected the data to two treatments: (a) we excluded reaction times less than $300 \mathrm{~ms}$ and more than 3,000 ms (resulting in the loss of fewer than $3 \%$ of trials), and (b) we reciprocally transformed the reaction times, which had the effect of creating a measure of reaction speed.

We next sought to test the predicted relationship between WICIAT scores and reaction latencies in the racial categorization task. That is, we hypothesized that, compared with low scorers on the WICIAT, high-WICIAT participants would take longer to categorize the race-ambiguous faces near the center of the morphing continuum-but not the unambiguous faces near the endpoints. We used hierarchical linear modeling to test the effects of implicit White identity centrality and implicit White ingroup preference on reaction latencies in the categorization task.

Level-1 equation. We expected participants' reaction latencies to exhibit a strong quadratic trend, such that faces in the racially ambiguous middle of the Black-White continuum were categorized more slowly than faces at the endpoints of the continuum. Thus, we modeled participants' reaction latencies using the following quadratic Level-1 (within-subject) equation:

$$
\text { Level 1: } \operatorname{SPEED}_{t i}=\pi_{0 i}+\pi_{1 i}(\mathrm{MR})_{t i}+\pi_{2 i}(\mathrm{MR})_{t i}^{2}+e_{t i}
$$

In this equation, $\mathrm{MR}_{t i}$ is the morphing ratio from 0 to 1 of a face, $t$, presented to a participant, $i$, with higher values indicating greater "Whiteness." Variable SPEED ${ }_{t i}$ is the speed with which the participant categorized the face. Parameter $\pi_{0 i}$ represents the intercept around which the participant's reaction latencies varied, $\pi_{1 i}$ represents the linear trend of the participant's reaction latencies over the range of morphing ratios, and $\pi_{2 i}$ represents the quadratic trend - that is, curvature - of participant's reaction speed function.

Level-2 equations. We sought to determine the effects of our between-subjects variables-that is, WICIAT score (WIC) and White ingroup preference IAT score (WIP) - on the shape of participants' reaction latency curves, defined by parameters $\pi_{\mathrm{O} i}$, $\pi_{1 i}$, and $\pi_{2 i}$. Thus, we constructed the following between-subjects (Level-2) equations:

$$
\begin{gathered}
\text { Level 2: } \pi_{0 i}=\beta_{00}+\beta_{01}(\mathrm{WIC})_{i}+\beta_{02}(\mathrm{WIP})_{i}+r_{0 i} \\
\pi_{1 i}=\beta_{10}+\beta_{11}(\mathrm{WIC})_{i}+\beta_{12}(\mathrm{WIP})_{i}+r_{1 i} \\
\pi_{2 i}=\beta_{20}+\beta_{21}(\mathrm{WIC})_{i}+\beta_{22}(\mathrm{WIP})_{i}+r_{2 i}
\end{gathered}
$$

Here, $\beta_{00}, \beta_{10}$, and $\beta_{20}$ represent the means around which individuals' reaction speed curves differ in their intercepts $\left(\pi_{0 i}\right)$, linear trends $\left(\pi_{1 i}\right)$, and quadratic trends $\left(\pi_{2 i}\right)$, respectively. $\beta_{10}$, $\beta_{11}$, and $\beta_{12}$ represent the influence of WICIAT score on these Level-1 effects, and $\beta_{20}$ and $\beta_{21}, \beta_{22}$ represent the influence of White ingroup preference score. $r_{0 i}, r_{1 i}$, and $\mathrm{r}_{2 i}$ represent random between-subjects error. The category latency effect-that is, the degree to which participants' categorization speeds are depressed near the middle of the morphing continuum - is associated with the quadratic trend $\left(\pi_{2 i}\right)$ in participants' responses.

Solution. We used HLM 6 to solve the two-level model described above. The overall intercept for the model, $\beta_{00}$, was 1.51 , $S E \beta_{00}=0.025, t(112)=59.49, p<.01$, indicating that participants took an average of $662 \mathrm{~ms}$ to categorize faces in the race-categorization task. The average linear trend was not significant, $\beta_{10}=-0.0019, S E \beta_{10}=0.0021, t(113)=-0.88, p=.39$, indicating that morphing ratio had a nonsignificant overall effect on the participants' categorization latencies across morphing ratios. The intercept for the quadratic trend was highly significant, $\beta_{20}=0.019, S E \beta_{20}=0.00077, t(113)=24.28, p<.01$, indicating that, as expected, participants' reaction speeds were lower in the middle of the morphing continuum than at the endpoints. As hypothesized, WICIAT score modified this quadratic trend, $\beta_{21}=0.0029, S E \beta_{21}=0.0018, t(113)=1.98, p<.05$. White ingroup preference IAT score did not significantly qualify any of the within-subject effects (i.e., intercept, linear trend, or quadratic trend).

In order to visualize the effect of participants' WICIAT scores on reaction latencies in the race-categorization task, we plotted predicted reaction speed curves-converting speeds back into latencies - at one standard deviation above and one below the mean on the WICIAT (cf. Aiken \& West, 1991). Thus, these curves represent participants' categorization latencies as a function of morphing ratio at low and high levels of implicit White identity centrality. As can be seen in Figure 4B, WICIAT score predicted participants' reaction latency profiles such that high-WICIAT participants took an especially long time to categorize raceambiguous faces.

\section{Discussion}

Experiment 3 replicated previously observed relationships between levels of ingroup identification and two racial categorization phenomena. First, the WICIAT successfully predicted the ingroup overexclusion effect (Castano et al., 2002) in a Black-White racial categorization task. As predicted, participants scoring high on the WICIAT tended to exclude racially ambiguous faces from the White ingroup (as measured by Black-White categorization threshold) more than did weakly identified participants (Figure 4A). Second, the WICIAT predicted the categorization latency effect (Blascovich et al., 1997) in the same task. White participants scoring high on the WICIAT tended to scrutinize race-ambiguous faces (those near the middle of the Black-White morphing continuum) significantly longer than did low-WICIAT participants (Figure 4B). When pitted against a commonly used measure of White ingroup preference-specifically, the White ingroup preference IAT-only the WICIAT predicted either of these racial

\footnotetext{
${ }^{7}$ Categorization threshold may also be assessed in terms of the total number of faces participants categorize as White (see Castano et al., 2002). Using linear regression, we regressed total "White" categorizations onto participants' WICIAT and White ingroup preference IAT scores. Whereas ingroup preference had no effect on the number of "White" categorizations ( $B=0.11, S E B=1.13, \beta=0.01, p=.92)$, high scorers on WICIAT categorized significantly fewer faces as White than did low-WICIAT participants $(B=-2.62, S E B=1.02, \beta=-0.28, p<.05)$.
} 
categorization phenomena. These findings provide strong support for the validity of the WICIAT as a measure of White identity centrality and suggest that White identification serves to link evaluations of the self to those of the ingroup (see Figure 1).

Thus far, we have examined cognitive correlates of the WICIAT (e.g., racial categorization phenomena). However, social identification also has affective implications, and White ingroup identification should be no exception. Some Whites have been shown to experience negative self-evaluative emotions (e.g., guilt) when considering their group's transgressions against racial minorities (Iyer et al., 2003; Swim \& Miller, 1999). Moreover, White guilt has been shown to increase with "group-based self-focus," or cognizance of membership in the offending group (Iyer et al., 2003). Because the WICIAT can be thought of as a measure of chronic cognizance of membership in the White group, we expected WICIAT scores to predict Whites' levels of self-evaluative emotion (i.e., guilt, shame, and embarrassment) upon being made aware of their group's transgressions. In Study 4, we presented Whites with an account of Black lynchings in the late 19th and early 20th century. We predicted that high scorers on the WICIAT would experience more negative self-evaluative emotion than would low-WICIAT participants. However, we expected no association between WICIAT scores and negative other-focused emotions (i.e., anger and sadness).

\section{Study 4}

\section{Method}

\section{Participants}

Thirty-two students (22 women, 10 men) at Stanford University took part in the current study. Participants were each paid $\$ 10$. Participants who had identified their only race or ethnicity to be White during a mass data collection at the beginning of the term were selected (Hispanic Whites were thus not included as participants).

\section{Materials and Measures}

The lynching story. The account of Black lynchings used in the current study was culled by the authors from several Internet sources, including the Public Broadcasting System's American Experience Web site. The 800word story contained accounts of the false imprisonment, lynching, and mutilation of Blacks by Whites; the fear this caused in Black communities; and widespread popular support for these actions among Southern Whites. ${ }^{8}$

WICIAT. Participants were administered the WICIAT, which is described in Study 1.

Measures of White ingroup preference. Preference for the White ingroup relative to the Black outgroup might be expected to correlate with emotional reactions to White transgressions. Thus, in order to control for White ingroup preference in subsequent analyses, we administered implicit and explicit measures of the construct-namely, the White ingroup preference IAT and the MRS. The latter questionnaire exhibited adequate internal reliability $(\alpha=.89)$.

Emotion ratings. In order to gauge participants' self-evaluative and other-directed emotions after reading the lynching story, we administered an emotional experience questionnaire. In the questionnaire, participants were shown 15 emotion adjectives in random order and were asked to rate the degree to which they were currently experiencing each. Participants made their ratings on a scale ranging from 1 (not at all) to 10 (very intensely). Included among the adjectives were the self-evaluative emo- tions (i.e., guilt, shame, and embarrassment) and other-directed emotions (i.e., anger and sadness) of interest.

White Guilt Scale. As another measure of self-evaluative emotional reactions to the lynching story, we administered Swim and Miller's (1999) five-item White Guilt Scale. This scale gauges Whites' general feelings of guilt about past and present social inequality between Whites and Blacks. Participants rated their agreement to each question on a 7-point scale, ranging from 1 (disagree strongly) to 7 (agree strongly). The scale exhibited adequate internal reliability $(\alpha=.86)$.

\section{Procedure}

Participants were run in groups of 1-4. Upon arrival, participants were seated at testing computers, which were separated by dividers. Experimental materials were presented with MediaLab and DirectRT. Participants were first administered the WICIAT, followed by implicit and explicit measures of ingroup preference. Then, after an unrelated filler task, participants read the lynching story. Finally, participants completed the emotional experience questionnaire and the White Guilt Scale. Participants were then debriefed as to the nature of the study and dismissed.

\section{Results}

Participants' gender was not significantly associated with any measure administered in Study 4. Nor did gender moderate the relationship between WICIAT scores and any outcome measure. We therefore collapsed across gender in the analyses reported here.

\section{Calculation of IAT Scores}

WICIAT and White ingroup preference IAT scores were computed in the manner described in Study 1, such that higher scores reflect greater implicit White identity centrality and implicit preference for the White ingroup.

\section{WICIAT Scores and Emotional Reactions to Lynching Story}

Adjective ratings. We first sought to test the relationship between WICIAT scores and emotion adjective ratings, while controlling for levels of implicit and explicit ingroup preference. Using simultaneous linear regression, we regressed ratings of each relevant emotion (i.e., guilt, shame, embarrassment, anger, and sadness) onto WICIAT, White ingroup preference IAT, and MRS scores. The WICIAT did not significantly predict guilt adjective ratings $(B=0.96, S E B=0.97, \beta=0.19, p=.33)$. As hypothesized, however, WICIAT scores were positively associated with levels of shame ( $B=2.16, S E B=1.11, \beta=0.38, p=.06)$, and embarrassment $(B=2.48, S E B=0.95, \beta=0.50, p<.05)$. The WICIAT did not significantly predict ratings of anger $(B=$ 0.14 , SE $B=1.15, \beta=0.03, p=.90)$, or sadness $(B=1.47, S E$ $B=1.05, \beta=0.28, p=.17$ ).

White Guilt Scale. We next tested whether the WICIAT predicted scores on the White Guilt Scale, again controlling for implicit and explicit ingroup preference. As predicted, the

\footnotetext{
${ }^{8}$ In a pretest, the lynching story was shown to increase Whites' experience of negative self-evaluative emotions (i.e., guilt, shame, and embarrassment) and other-focused emotions (i.e., sadness and anger) compared with a neutral story of the same length.
} 
WICIAT was significantly positively associated with White guilt $(B=1.32$, SE $B=0.54, \beta=0.43, p<.05)$.

Self-evaluative versus other-directed emotion. Next, we examined whether the WICIAT was differentially predictive of selfevaluative and other-directed emotions. We began by aggregating indices of self-evaluative emotion (i.e., adjective ratings of shame, embarrassment, and guilt, and scores on the White Guilt Scale) and other-directed emotion (i.e., adjective ratings of anger and sadness) to form overall measures of each emotion type. Then, using the MIXED procedure in SAS (Version 8), we tested the effects of WICIAT score, emotion type (self-evaluative vs. other-directed), and the Emotion Type $\times$ WICIAT Score interaction on emotion levels, while controlling for implicit and explicit ingroup preference scores. We observed a significant main effect of emotion type, such that participants experienced more other-directed emotion than self-evaluative emotion, $t(30)=3.14, p<.01$. We also observed a significant main effect of WICIAT score, such that high-WICIAT participants experienced more negative emotion than did low-WICIAT participants, $t(30)=2.54, p<.05$. Most important, as predicted, emotion type significantly moderated the effect of WICIAT score on emotion levels, $t(30)=1.99, p<.05$. In order to visualize the Emotion Type $\times$ WICIAT Score interaction, we graphed it according to techniques articulated by Aiken and West (1991). As can be seen in Figure 5, the Emotion Type $\times$ WICIAT Score interaction reflects the fact that WICIAT scores were more strongly positively associated with self-evaluative emotions (i.e., guilt, shame, and embarrassment) than with otherdirected emotions (i.e., anger and sadness).

\section{Discussion}

Study 4 provides affective evidence for the validity of the WICIAT. After reading about moral transgressions of the White

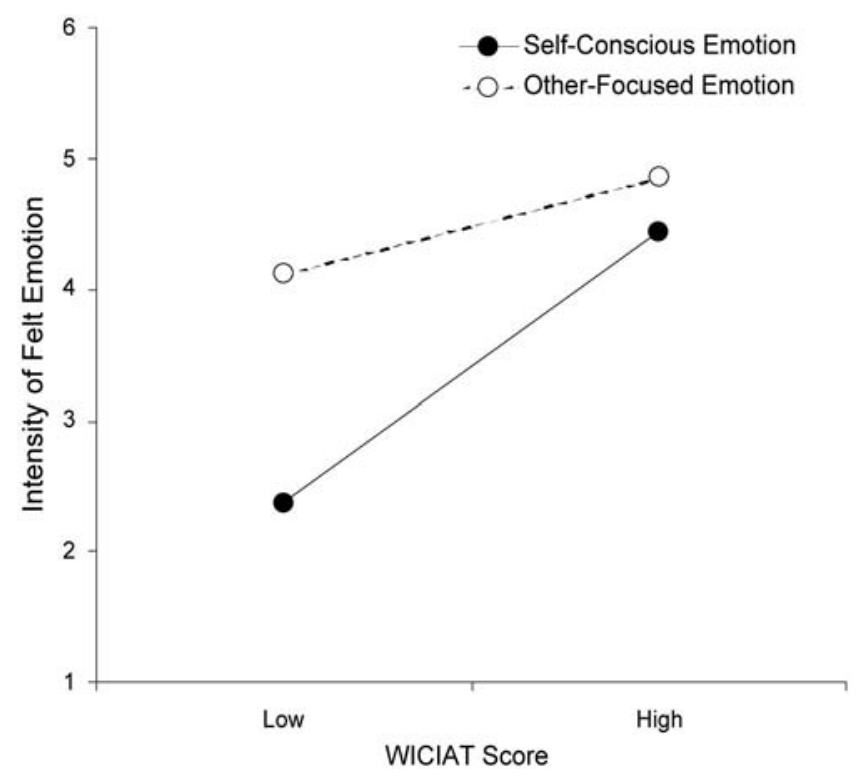

Figure 5. Whites' levels of negative other-focused emotion (anger and sadness) and self-evaluative emotion (guilt, shame, and embarrassment) after reading about moral transgressions of the ingroup in Study 4. WICIAT $=$ White Identity Centrality Implicit Association Test. ingroup-namely, the epidemic of Black lynchings in American history-high-WICIAT participants experienced higher levels of negative self-evaluative emotion (i.e., guilt, shame, and embarrassment) than did low-WICIAT individuals. It is important to note that this is not merely the result of the general tendency of high-WICIAT participants to experience negative affect because WICIAT scores had no significant effect on levels of negative other-directed emotion (i.e., sadness and anger). In addition to attesting to the WICIAT's validity, these findings suggest that high-WICIAT Whites take ingroup transgressions to reflect negatively on themselves and, thus, that White identity has the consequence of linking self- and ingroup-evaluations.

\section{General Discussion}

We reported the development and validation of a measure of White racial identification based on the IAT (Greenwald et al., 1998). The WICIAT, which measures the incorporation of White ingroup membership into the self-concept, was found to correlate with five convergent validation criteria: (a) response latencies in Smith and Henry's (1996) trait self-descriptiveness task, (b) an index of participants' likely history of interracial association (i.e., the relative size of the non-White population in participants' home counties; McGuire et al., 1978; Perry, 2002), (c) the ingroup overexclusion effect (Castano et al., 2002; Leyens \& Yzerbyt, 1992; Yzerbyt et al., 1995) in Black-White racial categorization, (d) the categorization latency effect (Blascovich et al., 1997) in racial categorization, and (e) self-evaluative emotional reactions to ingroup moral transgressions. Evidence for the discriminant validity of the WICIAT comes from the fact that the instrument did not correlate highly with theoretically distinct measures, including implicit (Greenwald et al., 1998) and explicit (McConahay et al., 1981) measures of ingroup preference and explicit measures of White identity (Luhtanen \& Crocker, 1992; Sellers et al., 1997; Tropp \& Wright, 2001). Together, these findings make a strong case for the construct validity of the WICIAT, as well as the validity of our proposed model of the antecedents and consequences of identification with the White group (see Figure 1). ${ }^{9}$

\section{Substantive Implications}

We emphasized from the outset that our validation criteria (see Table 1), in addition to providing useful references against which to evaluate the WICIAT, also constitute interesting and important phenomena in their own right. The current findings both inform our understanding of the general social psychological mechanisms

\footnotetext{
${ }^{9}$ Given that we used Smith and Henry's (1996) trait self-descriptiveness task as a criterion against which to validate the WICIAT, researchers might wonder why they should use the WICIAT - and not the trait task-to assess White identification. We see the WICIAT as having at least two advantages. First, the WICIAT takes much less time to administer-in our studies, it took an average of approximately $3 \mathrm{~min}$ versus $10 \mathrm{~min}$ for the trait task. Second, the IAT framework has been the subject of a great deal of psychometric study (Cunningham, Preacher, \& Banaji, 2001; Greenwald et al., 1998; Greenwald \& Nosek, 2001; Greenwald, Nosek, \& Banaji, 2003). To our knowledge, the trait self-descriptiveness task has not been groomed for general use as an individual difference measure. We thank an anonymous reviewer for raising this concern.
} 
that these phenomena reflect and provide specific insights into the nature of White ingroup identification.

\section{Social Exposure to Non-Whites}

The relationship between implicit White identity centrality and participants' history of interracial association lends credence to arguments that perceptual distinctiveness of one's race in part determines levels of racial identification (McGuire et al., 1978; Turner et al., 1987). In addition, the influence of interracial association on White identification places important limits on the notion that Whiteness, in virtue of being hegemonic, is "unmarked" and invisible to those who possess it (Delgado \& Stefancic, 1997). Rather, our findings support recent ethnographic claims that White identity is invisible only to Whites who have little contact with people of color (Frankenberg, 1993; McIntyre, 1997; Perry, 2002).

\section{Racial Categorization Phenomena}

\section{The Ingroup Overexclusion Effect}

The ingroup overexclusion effect has particular historical resonance for race relations in the United States. American Whites have historically exhibited a reluctance to categorize mixed-race (i.e., racially ambiguous) individuals as White (e.g., Grant, 1916), and history has seen repeated attempts to codify into law an "overexclusive" definition of Whiteness. The Virginia Racial Integrity Act of 1924, for instance, stated that "the term 'White person' shall apply only to such person as has no trace whatever of any blood other than Caucasian." 10 It has even been suggested that the very concept White is a social construction founded on purity from outgroup heritage (Haney-Lopez, 1996). The success of the WICIAT in predicting the ingroup overexclusion effect in WhiteBlack racial categorization suggests that White ingroup identification may be one mechanism behind these historical and legal phenomena.

Beyond these implications for racial categorization among Whites, the current research contributes to our understanding of the mechanisms behind the ingroup overexclusion effect generally. Previous research has often attributed the bias to ingroup preference (Himmelfarb, 1966; Lindzey \& Rogolsky, 1950; Quanty, Keats, \& Harkins, 1975). However, the current research is consonant with more recent work (Castano et al., 2002) suggesting that ingroup identification is the primary determinant of individuals' tendency to overexclude.

\section{The Categorization Latency Effect}

Our findings concerning the categorization latency effect bolster and clarify the conclusions of Blascovich et al. (1997). In this research, Whites scoring high on the MRS were found to spend a relatively long time categorizing Black-White ambiguous facesevidence that these individuals sought to be generally accurate in their categorizations. Despite employing a measure of prejudice, Blascovich and colleagues (1997) attributed the latency effect to ingroup identification. Thus, it is unclear which of these (often correlated) factors actually produces the effect. By measuring ingroup identification and ingroup preference independently, the current research disambiguates these variables. Supporting Blas- covich et al.'s (1997) conclusions, we found that the categorization latency effect was associated with ingroup identification but not with ingroup preference.

\section{Ingroup Identification and Emotional Reactions to Ingroup Transgressions}

In Study 4, highly ingroup-identified Whites were found to experience elevated levels of self-evaluative (but not otherdirected) emotion after reading about the historical oppression of Blacks by Whites. This finding provides evidence for the construct validity of White guilt (Iyer et al., 2003; Swim \& Miller, 1999) and lends credence to Iyer and colleagues' (2003) proposal that White guilt stems, in part, from Whites' self-focus in terms of group membership.

\section{A Multidimensional Model of White Identity?}

In conceptualizing White identity as the merging of representations of the self and the White ingroup, the current work addresses only one potential dimension of White identity. Indeed, many forms of social identity are multidimensional in nature, encompassing affective, motivational, and behavioral elements (Deaux, 1996; Jackson \& Smith, 1999). Sellers and colleagues (1997) echoed this in the context of race, noting that racial identity consists not only of one's definition of self, but also of one's attitudes and ideologies regarding the racial ingroup. Therefore, in order to gain a fuller understanding of White identity, the WICIAT should be supplemented with measures of additional facets of identity. It may eventually be possible to construct a "multidimensional model of White identity" to parallel Sellers et al.'s (1997) model of Black identity. Toward this end, we consider what the White counterparts to the MIBI dimensions might be.

Identity centrality. As noted earlier, implicit White identity centrality is conceptually quite similar to the Centrality dimension of the MIBI. The current research suggests that interracial association is an important determinant of the degree to which Whites reflexively define themselves in terms of Whiteness. Specifically, social exposure to non-Whites-such as that possible in diverse childhood environments-leads to high levels of White identification.

Evaluation of the ingroup. In the MIBI, evaluation of the Black ingroup (the Regard dimension) constitutes an attitudinal dimension of identity. In the context of White identity, evaluative bias toward the White ingroup (i.e., ingroup preference), as measured by the ingroup preference IAT (Greenwald et al., 1998), might be seen as a parallel attitudinal dimension of White identity.

Ideology. In our view, the most difficult challenge in constructing a multidimensional portrait of White racial identification concerns the qualitative, ideological contents of identity. Using the MIBI as a guide, ideologies associated with White identity might include a wide range of sociopolitical views concerning how Whites ought to perceive, relate to, and behave toward nonWhites. The colorblind-multicultural dimension has received attention in sociology (e.g., Frankenberg, 1993; Perry, 2002) and

\footnotetext{
${ }^{10}$ The Supreme Court invalidated the act in 1967 (Loving v. Virginia, 1967).
} 
social psychology (e.g., Wolsko, Park, Judd, \& Wittenbrink, 2000). Colorblind ideology is marked by the belief that all human beings are the same "under the skin" and that ethnic differences should be de-emphasized - and, if possible, go unnoticed (Dyson, 2000; Frankenberg, 1993; Wolsko et al., 2000). A multicultural (or "race-cognizant") ideology, in contrast, is marked by the belief that important cultural differences exist between members of different racial and ethnic groups and that these differences have a profound influence on group members' experiences (Frankenberg, 1993; Wolsko et al., 2000).

The ideological dimensions of White ingroup identification might also include individuals' views concerning their own cultural status. On the basis of ethnographic data, Perry (2002) identifies three White identity ideologies: (a) White-as-norm identity, in which the individual defines herself merely through negation (e.g., not being Black), (b) postcultural identity, which explicitly rejects indebtedness to the past and espouses that human actualization requires "getting over" culture, and (c) symbolicethnic identity, which embraces European immigrant ancestries (e.g., Irish). We would also propose the existence of a fourth form of White identity: power-cognizant identity. Power-cognizant Whites are acutely aware of their unearned privilege - and believe that Whiteness is, in a quite real sense, a system for restricting the allocation of resources in a stratified society (cf. Haney-Lopez, 1996).

Research should examine links between different levels of identity centrality and different ideological components of White ingroup identification. For instance, Perry (2002) notes that her White informants who had trouble introspecting and speaking about their racial identity (and who thus might be expected to score low on the WICIAT) tended to exhibit a White-as-norm identity. In contrast, White individuals who reflexively defined themselves in terms of race tended to vary widely in the content of identity, exhibiting, in various nuanced forms, postcultural and symbolicethnic identities.

\section{Cultural Generalizability of the Current Approach}

The current research was conducted in the United States, and it is not entirely clear how well our approach would generalize to other cultures. We can speculate, however. The issue of generalizability suggests two questions. First, to what extent can the WICIAT be used to measure identity among Whites in cultures in which Whites are not the dominant group? We would expect the WICIAT to constitute an effective measure of nondominant White identities. Although we have claimed that the measurement of identity centrality among dominant-group members benefits from an implicit measure like the WICIAT, we do not claim that such a measure is inadequate for measuring nondominant identities. Second, to what extent would a measure similar to the WICIAT provide a uniquely effective measure of non-White dominant identities? We have argued that group dominance-being the most powerful group - is what lends implicit measures their unique effectiveness. Thus, we believe that a measure similar to the WICIAT would be particularly effective in measuring non-White dominant identities (e.g., Chinese in Singapore).

\section{Measuring Other Types of Identity}

We have suggested that the WICIAT owes its unique effectiveness in part to Whites' position at the top of the social hierarchy. A long history of social dominance, the argument goes, has instilled many Whites with a reluctance to acknowledge the importance of race generally, or of their Whiteness in particular (BonillaSilva, 2003; Frankenberg, 1993). Though the IAT may prove useful in measuring many forms of dominant-group identity, it would be overreaching to claim that any dominant identity is best measured by using this framework or that the IAT is not uniquely useful in measuring certain nondominant identities. Instead, implicit measures are indicated whenever an identity-dominant or not-is likely to be associated with strong self-presentational mores. Thus, though male is certainly a dominant-group identity, it is much more socially unacceptable to reflect publicly or privately on one's maleness than on one's Whiteness. Conversely, stigmatized identities (e.g., homosexual), though certainly not dominant, might best be assessed by using implicit measures. These caveats notwithstanding, powerful groups may, as a general rule, reinforce their dominance by fostering ideologies (e.g., colorblindness) that render self-critique difficult-thus creating selfpresentational proscriptions that render implicit measures uniquely effective. We believe that the potentially complex relationship between societal dominance and such mores deserves further study.

\section{Racial Inequality and Discrimination Revisited}

As noted at the outset, the psychological study of racial inequality and discrimination has been dominated by a prejudice-centered approach (Mackie \& Smith, 1998). Nonetheless, recent research suggests that Whites' experience of their own racial identity may impact intergroup behavior independent of attitudes toward nonWhites (Branscombe, 1998; Brewer, 1999; Gaertner et al., 1997; Iyer et al., 2003; Lowery et al., 2004; Sidanius et al., 2004). The current work adds to this growing body of evidence. In testing relationships between the WICIAT and hypothesized consequences of White identity centrality (i.e., the ingroup overexclusion effect, the categorization latency effect, and self-evaluative emotional reactions to ingroup transgressions), we were careful to control for implicit and explicit racial attitudes. That these relationships remained robust indicates that such attitudes did not mediate the effects of White identity centrality.

But what do these effects have to do with racial inequality and discrimination? An example illustrates the potential relevance of White identity centrality - and thus the WICIAT - to these problems. Some commentators (e.g., Bonilla-Silva, 2003) have argued that White opposition to redistributive social policies, such as affirmative action, impedes efforts to alleviate racial inequality in the United States. White identity centrality may, through a host of mechanisms, influence attitudes toward this consequential public policy. In one such mechanism, suggested by the current findings, White identity centrality heightens Whites' experience of negative self-evaluative emotions (e.g., guilt, shame, and embarrassment) when considering anti-Black injustice; these emotions, in turn, elevate support for affirmative action (Iyer et al., 2003; Swim \& Miller, 1999). Thus, one might hypothesize that White identity centrality is positively associated with support for affirmative 
action. Through its influence on variables other than selfevaluative affect, White identification may push affirmative action attitudes in the opposite direction. For instance, social identity theory (Tajfel, 1978) implies a positive association between White identification and negative attitudes toward Blacks; negative outgroup attitudes should, in turn, reduce support for affirmative action (Federico \& Sidanius, 2002). Finally, White identification may sensitize Whites to the ways in which their own social and economic fortunes are tied to that of the ingroup. A widespread belief exists among Whites that affirmative action threatens the opportunities of the White group as a whole (Crosby, 2004); White identification might be expected to extend these negative expectations to the self and thus to reduce support for affirmative action. These possibilities suggest that the WICIAT can be an important tool for researchers seeking to explain the forces that create and sustain inequality.

\section{References}

Aiken, L. S., \& West, S. G. (1991). Multiple regression: Testing and interpreting interactions. Thousand Oaks, CA: Sage.

Aron, A., Aron, E. N., Tudor, M., \& Nelson, G. (1991). Close relationships as including other in the self. Journal of Personality and Social Psychology, 60, 241-253.

Blalock, H. M. (1972). Social statistics (2nd ed.). New York: McGrawHill.

Blascovich, J., Wyer, N. A., Swart, L. A., \& Kibler, J. L. (1997). Racism and racial categorization. Journal of Personality and Social Psychology, 72, 1364-1372.

Bonilla-Silva, E. (2003). Racism without racists: Color-blind racism and the persistence of racial inequality in the United States. Lanham, MD: Rowman \& Littlefield.

Branscombe, N. R. (1998). Thinking about one's gender group's privileges or disadvantages: Consequences for well-being in women and men. British Journal of Social Psychology, 37, 167-184.

Brewer, M. B. (1999). The psychology of prejudice: Ingroup love or outgroup hate? Journal of Social Issues, 55, 429-444.

Brown, M. K., Carnoy, M., Currie, E., Duster, T., Oppenheimer, D. B., Schultz, M. M., et al. (2003). Whitewashing race: The myth of a color-blind society. Berkeley, CA: University of California Press.

Bryk, A. S., \& Raudenbush, S. W. (1992). Hierarchical linear models: Applications and data analysis methods. Thousand Oaks, CA: Sage.

Castano, E., Yzerbyt, V., Bourguignon, D., \& Seron, E. (2002). Who may enter? The impact of ingroup identification on ingroup/outgroup categorization. Journal of Experimental Social Psychology, 38, 315-322.

Cohen, J. (1977). Statistical power analysis for the behavioral sciences (Rev. ed.). Hillsdale, NJ: Erlbaum.

Cohen, J. D., MacWhinney, B., Flatt, M., \& Provost, J. (1993). PsyScope: An interactive graphic system for designing and controlling experiments in the psychology laboratory using Macintosh computers. Behavior Research Methods, Instruments, \& Computers, 25, 257-271.

Crosby, F. J. (2004). Affirmative action is dead: Long live affirmative action. New Haven, CT: Yale University Press.

Cross, W. E. (1991). Shades of black: Diversity in African American identity. Philadelphia: Temple University Press.

Cunningham, W. A., Preacher, K. J., \& Banaji, M. R. (2001). Implicit attitude measures: Consistency, stability, and convergent validity. Psychological Science, 12, 163-170.

Deaux, K. (1996). Social identification. In E. T. Higgins \& A. W. Kruglanski (Eds.), Social psychology: Handbook of basic principles (pp. 777798). New York: Guilford Press.

Delgado, R., \& Stefancic, J. (1997). Critical white studies: Looking behind the mirror. Philadelphia: Temple University Press.
Draine, S. C. (1998). Inquisit (Version 1.33) [Computer software]. Seattle, WA: Millisecond Software.

Dyson, M. E. (2000). I may not get there with you: The true Martin Luther King, Jr. New York: Free Press.

Eisenberg, N. (2000). Emotion, regulation, and moral development. Annual Review of Psychology, 51, 665-697.

Federico, C. M., \& Sidanius, J. (2002). Racism, ideology, and affirmative action revisited: The antecedents and consequences of "principled objections" to affirmative action. Journal of Personality and Social Psychology, 82, 488-502.

Flagg, B. J. (1993). "Was blind, but now I see": White race consciousness and the requirement of discriminatory intent. Michigan Law Review, 91, 953-1017.

Frankenberg, R. (1993). White women, race matters: The social construction of whiteness. Minneapolis: University of Minnesota Press.

Frankenberg, R. (2001). The mirage of an unmarked whiteness. In B. Brander Rasmussen, M. Klinenberg, I. J. Nexica, \& M. Wray (Eds.), The making and unmaking of whiteness (pp. 72-96). Durham, NC: Duke University Press.

Gaertner, S. L., Dovidio, J. F., Banker, B. S., Rust, M. C., Nier, J. A., Mottola, G. R., et al. (1997). Does white racism necessarily mean antiblackness? Aversive racism and pro-whiteness. In M. Fine, L. Weis, L. C. Powell, \& L. M. Wong (Eds.), Off white: Readings on race, power, and society (pp. 167-178). New York: Routledge.

Grant, M. (1916). The passing of the great race: The racial basis of European history. New York: Scribner.

Greenwald, A. G., \& Banaji, M. R. (1995). Implicit social cognition: Attitudes, self-esteem, and stereotypes. Psychological Review, 102, $4-27$.

Greenwald, A. G., Banaji, M. R., Rudman, L. A., Farnham, S. D., Nosek, B. A., \& Mellott, D. S. (2002). A unified theory of implicit attitudes, stereotypes, self-esteem, and self-concept. Psychological Review, 109, $3-25$.

Greenwald, A. G., \& Farnham, S. D. (2000). Using the Implicit Association Test to measure self-esteem and self-concept. Journal of Personality and Social Psychology, 79, 1022-1038.

Greenwald, A. G., McGhee, D. E., \& Schwartz, J. L. K. (1998). Measuring individual differences in implicit cognition: The Implicit Association Test. Journal of Personality and Social Psychology, 74, 1464-1480.

Greenwald, A. G., \& Nosek, B. A. (2001). Health of the Implicit Association Test at age 3. Zeitschrift für Experimentelle Psychologie, 48, $85-93$.

Greenwald, A. G., Nosek, B. A., \& Banaji, M. R. (2003). Understanding and using the Implicit Association Test: I. An improved scoring algorithm. Journal of Personality and Social Psychology, 85, 197-216.

Haney-Lopez, I. (1996). White by law: The legal construction of race. New York: New York University Press.

Helms, J. E. (1994). The conceptualization of racial identity and other "racial" constructs. In E. J. Trickett, R. J. Watts, \& D. Birman (Eds.), Human diversity: Perspectives on people in context (pp. 285-311). San Francisco: Jossey-Bass.

Himmelfarb, S. (1966). Studies in the perception of ethnic group members: I. Accuracy, response bias, and anti-Semitism. Journal of Personality and Social Psychology, 4, 347-355.

Iyer, A., Leach, C. W., \& Crosby, F. J. (2003). White guilt and racial compensation: The benefits and limits of self-focus. Personality and Social Psychology Bulletin, 29, 117-129.

Jackson, J. W., \& Smith, E. R. (1999). Conceptualizing social identity: A new framework and evidence for the impact of different dimensions. Personality and Social Psychology Bulletin, 25, 120-135.

Jarvis, B. G. (2004a). DirectRT (Version 2004.3.0.24) [Computer software]. New York: Empirisoft.

Jarvis, B. G. (2004b). MediaLab (Version 2004.3.14) [Computer software]. New York: Empirisoft. 
Leyens, J.-P., \& Yzerbyt, V. Y. (1992). The ingroup overexclusion effect: Impact of valence and confirmation on stereotypical information search. European Journal of Social Psychology, 22, 549-569.

Lindzey, G., \& Rogolsky, S. (1950). Prejudice and identification of minority group membership. Journal of Abnormal and Social Psychology, $45,37-53$.

Lipsitz, G. (1998). The possessive investment in whiteness: How white people profit from identity politics. Philadelphia: Temple University Press.

Loving v. Virginia, 388 U.S. 1 (1967). United States Reports, 388, 1.

Lowery, B. S., Unzueta, M., Knowles, E. D., \& Goff, P. A. (2004). Concern for the ingroup, apathy toward the outgroup, and opposition to affirmative action. Unpublished manuscript.

Luhtanen, R., \& Crocker, J. (1992). A collective self-esteem scale: Selfevaluation of one's social identity. Personality and Social Psychology Bulletin, 18, 302-318.

Mackie, D. M., \& Smith, E. R. (1998). Intergroup relations: Insights from a theoretically integrative approach. Psychological Review, 105, 499529

Maxwell, D. (1994). Morph (Version 2.5) [Computer software]. San Diego, CA: Gryphon Software Corporation.

McConahay, J. B., Hardee, B. B., \& Batts, V. (1981). Has racism declined in America? It depends on who is asking and what is asked. Journal of Conflict Resolution, 25, 563-579.

McGuire, W. J., McGuire, C. V., Child, P., \& Fujioka, T. (1978). Salience of ethnicity in the spontaneous self-concept as a function of one's ethnic distinctiveness in the social environment. Journal of Personality and Social Psychology, 36, 511-520.

McIntyre, A. (1997). Making meaning of whiteness: Exploring racial identity with white teachers. Albany: State University of New York Press.

Perry, P. (2001). White means never having to say you're ethnic: White youth and the construction of "cultureless" identities. Journal of Contemporary Ethnography, 30, 56-91.

Perry, P. (2002). Shades of white: White kids and racial identities in high school. Durham, NC: Duke University Press.

Phinney, J. S. (1990). Ethnic identity in adolescents and adults: Review of research. Psychological Bulletin, 108, 499-514.

Phinney, J. S. (1996). When we talk about American ethnic groups, what do we mean? American Psychologist, 51, 918-927.

Quanty, M. B., Keats, J. A., \& Harkins, S. G. (1975). Prejudice and criteria for identification of ethnic photographs. Journal of Personality and Social Psychology, 32, 449-454.

Ratcliff, R. (1993). Methods for dealing with reaction time outliers. Psychological Bulletin, 114, 510-532.

Raudenbush, S. W., Bryk, A. S., Cheong, Y. F., \& Congdon, R. (2004). Hierarchical linear and nonlinear modeling (Version 6.01a) [Computer software]. Lincolnwood, IL: Scientific Software International.
Rowley, S. J., Sellers, R. M., Chavous, T. M., \& Smith, M. A. (1998). The relationship between racial identity and self-esteem in African American college and high school students. Journal of Personality and Social Psychology, 74, 715-724.

Sellers, R. M., Rowley, S. A. J., Chavous, T. M., Shelton, J. N., \& Smith, M. A. (1997). Multidimensional Inventory of Black Identity: A preliminary investigation of reliability and construct validity. Journal of Personality and Social Psychology, 73, 805-815.

Sidanius, J., Van Laar, C., Levin, S., \& Sinclair, S. (2004). Ethnic enclaves and the dynamics of social identity on the college campus: The good, the bad, and the ugly. Journal of Personality and Social Psychology, 87, 96-110.

Smith, E. R., \& Henry, S. (1996). An ingroup becomes part of the self: Response time evidence. Personality and Social Psychology Bulletin, $22,635-642$

Smith, E. R., \& Zarate, M. A. (1992). Exemplar-based model of social judgment. Psychological Review, 99, 3-21.

Swim, J. K., \& Miller, D. L. (1999). White guilt: Its antecedents and consequences for attitudes toward affirmative action. Personality and Social Psychology Bulletin, 25, 500-514.

Tajfel, H. (1978). Social categorization, social identity, and social comparison. In H. Tajfel (Ed.), Differentiation between social groups: Studies in the social psychology of intergroup relations (pp. 62-76). New York: Academic Press.

Tajfel, H., \& Turner, J. C. (1986). The social identity theory of intergroup behavior. In S. Worschel \& W. G. Austin (Eds.), The social psychology of intergroup relations (pp. 7-24). Chicago: Nelson-Hall.

Tropp, L. R., \& Wright, S. C. (2001). Ingroup identification as the inclusion of ingroup in the self. Personality and Social Psychology Bulletin, 27, 585-600.

Turner, J. C., Hogg, M. A., Oakes, P. J., Reicher, S. D., \& Wetherell, M. S. (1987). Rediscovering the social group: A self-categorization theory. Cambridge, MA: Basil Blackwell.

Wolsko, C., Park, B., Judd, C. M., \& Wittenbrink, B. (2000). Framing interethnic ideology: Effects of multicultural and color-blind perspectives on judgments of groups and individuals. Journal of Personality and Social Psychology, 78, 635-654.

Yzerbyt, V. Y., Leyens, J.-P., \& Bellour, F. (1995). The ingroup overexclusion effect: Identity concerns in decisions about group membership. European Journal of Social Psychology, 25, 1-16.

Zarate, M. A., \& Smith, E. R. (1990). Person categorization and stereotyping. Social Cognition, 8, 161-185.

Received January 10, 2004 Revision received February 7, 2005 Accepted March 11, 2005 